Original Research Paper

\title{
Social Media-Facilitated Programming: An ARG Model for Collaborative Programming
}

\author{
Ahmad Al-Jarrah, Abdel Karim Baareh, Ahmad Smadi and Roba Jabali \\ Applied Science Department, Ajloun University College, Al-Balqa Applied University, Ajloun, Jordan \\ aljarrah@bau.edu.jo,baareh@bau.edu.jo,amhs1966@bau.edu.jo,robajabali@bau.edu.jo
}

\author{
Article history \\ Received: 09-02-2021 \\ Revised: 20-03-2021 \\ Accepted: 02-04-2021 \\ Corresponding Author: \\ Ahmad Al-Jarrah \\ Department of Applied Science, \\ Ajloun University College, Al- \\ Balqa Applied University, \\ Ajloun, Jordan \\ Email: aljarrah@bau.edu.jo
}

\begin{abstract}
Internet-based tools and social media are greatly developed in the tech world. Today, technology is widely accepted and used by all generations. These tools are great and very useful for students in terms of learning, collaboration and information sharing. We aim to present a model for learning programming in social learning environments with the context of the Affinity Research Group (ARG) model. The proposed model is called "Learning Programming in Social Environments within Affinity Group (LPSEAG)". We test the proposed model for two academic years. A comparative approach was used. In the experiment, we divide the students into two categories: (1) Learn programming in the context of using the LPSEAG model, (2) Learn programming in the context of social media groups. Qualitative and quantitative results are compared for the two categories. From the results obtained it was clearly found that the students' satisfaction was high on working within a group using the LPSEAG model compared to the responses of students that use social media groups only. Moreover, the quantitative results support the assumptions that the use of LPSEAG model in learning programming in the introductory programming courses enhances the learning outcomes. Learning programming in groups enhances the learning outcomes for students whatever the student's programming level. Teachers are encouraged to create students' programming groups and implement LPSEAG model to increase learning outcomes and facilitate learning environments for students over-distance. More researches are needed to develop CVLEs which encourage students to learn programming with teams over distance.
\end{abstract}

Keywords: Collaborative Virtual Learning Environments, Social Learning Environment, Social Media, Collaborative Learning, Virtual Group Study

\section{Introduction}

Social media became very popular in the last few years, it was rapidly growing and spread very fast between all the societies and countries, where the usage of Social media for learning purposes is one of the most important types of learning and usage. Many researchers studied the different types of effects of social learning usage on humans (Guntuku et al., 2019; Zhang et al., 2019; Riehm et al., 2019). Additionally, the effects of social media in learning contests were also studied from different types of perspectives. In this research, we study the effects of using Social Media (SM) with the Affinity Research Group Model (ARG) on the learning outcomes and how the merge of SM and ARG can enhance the learning collaboration process. The subjects of this study were the students in introductory programming courses. Many studies show that social media nowadays is used widely by students (Facebook, Twitter, WhatsApp, Istagram, etc.). According to the Facebook statistics (Park, 2019), the number of Facebook users is 1.62 billion users, where there are 2.45 billion monthly active users; the average of monthly active users is increased $8 \%$ yearly. More specifically, Facebook users can be categorized according to gender, education and social media usage; for example; $57 \%$ of users are males and $43 \%$ are female. Also, $82 \%$ of college students use Facebook daily (Park, 2019).

An official and important model called Affinity Research Group (ARG) model (Gates et al., 2008), is recommended to motivate undergraduate students to learn 
via the well-structured learning and organized research groups. This model prepares, leads and motivates students from different backgrounds, levels and fields to be very active in learning together as a group, plus cooperating, coordinating and inclusion in between (Gates et al., 1999; Kephart and Villa, 2008). The ARG model has proved its strength and validity by implementing it on different courses, topics and students from different and various backgrounds. The ARG model was applied in a bounded and temporally area known as face-to-face, which is usually available in the physical classroom. The problem with the temporal bounds is that the ARG teams operations are limited to a specific time period and have to be synchronized between the team members, which constitutes a block in using the ARG model widely in supporting the distributed and distanced learning for the online courses. Moreover, (Al-Jarrah and Pontelli, 2020) shows that the extension of the ARG to be a learning model in a collaborative virtual environment has significant effectiveness on learning programming for introductory programming courses (Al-Jarrah, 2016; Al-Jarrah and Pontelli, 2016).

Collaboration environments for programming within teams was highlighted 1980s (Constantine, 1995). But, by the end of 1990s, researchers start studying pair programming model as a programming methodology (Nawrocki and Wojciechowski, 2001). The pair programming was defined simply by allowing two programmers to collaborate together to solve a common task while they site in the same place; the first programmer is called driver and the second is called navigator (Arisholm et al., 2007; Begel and Nagappan, 2008; McDowell et al., 2002). The authors of (Al-Jarrah and Pontelli, 2014) implement the pair programming in a new programming environments that allow the two programmer to work together over distance instead of working in the same place. The results show that working over distance facilitates the programmer collaboration and enhance the learning programming environments. After that, an extension of the model was presented by (AlJarrah and Pontelli, 2016; 2020) that allow a group of programmer to work together where the group have more members with assigned roles in addition to the two main roles (driver and navigators). The proposed model in this research extend the pair programming model and ARG model in addition to the benefit of using social media in learning.

Actually, we suggested in this study to use the Learning Programming in Social Environments within Affinity Group (LPSEAG) model which is an extension of ARG model with the use of social media. LPSEAG encourages the use of the affinity distributed groups over social media that it depends on the use of Collaborative Virtual Environments (CVEs). In this research, we proposed the design of the LPSEAG model which is defined as a collaborative virtual model that allows a group of students over social media to work together to learn computer programming as they form an affinity group in the context of collaborative learning principles. Students learn programming in the presence of collaboration virtual environments that support the operations and interactions in the over-distance affinity group.

Furthermore, while we prepare the last draft of this paper, COVID-19 spread over the whole world. Everything in the world is almost shutdown; schools, universities, companies, etc. As everyone starts working online and uses the available services to assure that main life operations don't stop. Most of the universities around the world continue giving lectures online. This situation can be an additional motivation for everyone to develop an over distance learning model. The proposed model is founded to make sure the learning process continues with the achievement of having the best learning outcomes.

\section{Brief Literature Review}

\section{Social Media}

Internet-based tools and social media are greatly developed in the tech world. Today, technology is widely accepted and used by all generations. These tools are great and very useful for students in terms of learning, collaboration and information sharing. Additionally, numerous efforts led to the advent of Web 2.0 have been made to integrate social media into the entire learning environment for students (Dabbagh and Kitsantas, 2012). Where, Web users have become co-creators of social information about the boom in Social Media (SM) rather than just consumers of information and at the same time; Social media is increasingly being used to provide educational activities despite its heavy use of social contacts among the younger generation.

The Learning Management Systems (LMSs) as a traditionally based learning system are still used widely by many higher education institutions, where many researches proved that we can empower the learners by implementing social media in learning and education which arranges the learners learning activities according to the concepts of e-Learning. Furthermore, LMS doesn't use the full potential of social media - compared to Facebook, Twitter, etc. - to improve students' global participation in learning through Collaborative Learning (CL) in social environment.

Social media reformed depending on how software developers share resources to coordinate work and mining the information. Treude et al. (2012) discussed the opportunities and challenges for software developers that depend on web content coordinated by the crowd and this led him to imagine the future of an industry where individual developers take the advantage from and contribute to a body of knowledge sustained from the 
crowd using social media. Where the use of social media evolved programmers from isolated individuals (Book readers) to web managers with collaborations with other worldwide software developers and this results to a good programmer and an academic planner of collaborative software development.

Social Media contributes in face-to-face collaborative learning by introvert students in higher education. Voorn and Kommers (2013) find that social media is very helpful for increasing collaborative learning performance and selfconfidence since they feel that their true nature is hampered in face-to-face contact and they prefer to communicate via social media rather than face-to-face. Moreover, students wish their educators to make more use of social media. GitHub one of the tools that lower the barriers to join communities that work on development where it helps developers to contribute together with sharing information about development process (Storey et al., 2014). A culture of participatory development has led to a network of tightly interconnected ecosystems made up of developers, communities of practice, shared content and media channels.

The latest innovation, social networks are becoming vitally important due to the increasing focus on the concepts of coherent action and collaborative learning across the globe. The authors of (Sarwar et al., 2019) identified perceived pleasure and ease of use as major positive factors when using social media for learning as a motivation and intended structure. These tools also expose students to violent and aggressive content and interactions due to cyberbullying. All this distracts students from their desired learning outcomes. Arora $e t$ al. (2019) emphasis that engagement, outreach, sentiment and growth play a key role in determining the influences across various domains of e-commerce, viral marketing, social media marketing and brand management wherein the identification of key information propagators is essential.

Numerous systematic studies have identified and critically assessed the current knowledge based on how the integration of social media has been done into high school writing instructions, with a special focus on factors that have improved student learning and factors that have created barriers to student learning. The social media was founded to be a potential learning environment as an authenticated media, but the low percentage of students participation affects the effective implementation. Students nowadays spend more time on writing about social media than they spend in the classrooms where they develop a new way of writing rather than the traditional writing techniques (Galvin and Greenhow, 2020). Although several studies have explored informal adolescent literacy practices online, the research examines how these spaces can be effectively informed or used in the classroom The findings focused on trends in how social media affects student learning experiences that have been reflected. The social media application suite within the dataset.

Nowadays, social media affects human development and behaviors. In the research (Ricciardelli et al., 2020), students that work over social media in the United States have explored through the use of social media, where it has been suggested that spreading interests that fall within the occupational scope of working over social media explores variables of importance and ethical implications. Within the students' data are their use of social, their knowledge of social media and their attitudes towards it; The results reveal that working over social media makes students appear to have conflicting attitudes toward social media that sometimes interfere with their self-knowledge and their use of social media. It also touched on the implications of working over social media, including liberalizing professional ethics standards. Clarity of sense of self and others, additional effects of empathy and parenthood; And the growing need to validate information from reliable sources.

\section{Affinity Research Group (ARG) Model}

ARG was designed to be a very important learning and researching model for undergraduate students (Kephart and Villa, 2008). This model actually takes care of establishing dynamic learning and productive groups. It works on the basis of cooperation between the group members that may be faculty members, graduates and undergraduate's students (Kephart et al., 2008). Actually, the ARG model developed to allow the group members to learn, share and work on different goals and concepts. The opinions and suggestions of each member group are very important to achieve the success of the entire group according to the decided objectives. The ARG model encourages and motivates the research group to design an affinity for the specific research or learning topic (Gates et al., 2008), where the individual member's ability is increased to improve self-efficacy, explore new areas, enhance reading and writing skills, presenting and solving the different problems (Kephart et al., 2008).

According to different researchers in many fields, the use of ARG has been shown to lead to graduation of computer engineering and computer science students and improve their retention, particularly those that have low levels of confidence and have deficiencies (Kephart and Villa, 2008), the use of ARG improves their remembrance. The ARG depends on the diversity among the group members, which includes different experiences, that improves the students' abilities, knowledge and skills of the whole group due to the concepts of information sharing (Gates et al., 2008). The ARG techniques or philosophy works based on maximizing the ability for every student to reach his/her potential. The ARG model through its operations conscious rules which are explicit, 
leads the students in a cooperative environment to be consciously developed and trained. The member's dynamic roles assignment is aimed to improve the member's developing skills and responsibility of each one not only achieving team goals. According to the experiments, the ARG model works efficiently and successfully in increasing students' participation which enhances the quality of undergraduate students in advanced studies at the same time.

The constructed ARG model is mostly different from traditional models. The traditional model works based on pyramid/hierarchical structures, where the layers shows a decreases in authority and expertise levels. The ARG model mostly differs in several important aspects in spite of incorporate aspects of the traditional models (e.g., peerto-peer relationships between team members), this can be shown in Table 1 (Al-Jarrah and Pontelli, 2020).

So as we said before, ARG strength can be clearly seen when we apply it to groups that have different member capabilities and diversity among them in skills, education and experiences. ARG put the members in a motivated atmosphere that help them to actively participate and be creative.

The ARG model is usually used to improve the positive interaction, increasing the interdependence and the self confidence of each member in the groups; this will lead to the following results:

- $\quad$ Starting and keeping cooperative groups and subgroups

- Learning and acquiring the way of correct research ways by cooperating as a team which leads to progress in skills, way of thinking and solving problems

Actually, working in a structured way will allow the group members to:

- Improve and develop their domain expertise
- Improve their research thinking and problem solving

- Improve their team work, communications and problem understanding and solving

- Become active, experts and leaders in their fields

\section{Collaborative Virtual Environments (CVEs)}

Collaborative Virtual Environments (CVEs) support learning process over distributed world that can be used by multi-users (Liebregt, 2005). The author in (Greenhalgh, 2012) defines CVEs as a computer system that supports the human collaboration and communications on the bases of computer system. On the other hand, the authors of (Redfern and Galway, 2002) defined CVEs as virtual spaces or places enabled or distributed by a computer where people could contact and identify with others via virtual agents and objects. The author of (Liebregt, 2005) defined CVE as 'connected computer systems aimed at the fulfilling of certain collaborative task within a generated 3 -D virtual environment'. Collaborative virtual environments are used to provide infrastructure that authorize the collaboration and saving common task between a number of users regardless of the mutual physical location. Moreover, there are common points between the most collaborative virtual environments (Greenhalgh, 2012):

- CVEs support geographically dispersed users since they are multi user computer based systems

- Users using CVEs can communicate and collaborate in various ways

- Virtual environments are provided by CVEs where all activities take place in an imaginary space or world

- In the virtual environment, each user is represented clearly and visually (and audibly, etc.) to other users by an avatar

- Users are acting independently from each other

Table 1: ARG model Vs. traditional model

\begin{tabular}{|c|c|c|}
\hline Characteristic & ARG & Traditional models \\
\hline Leadership & $\begin{array}{l}\text { The position of leadership can be held by any } \\
\text { team member because each student acquires the } \\
\text { required skills and expertise in several aspects to be a } \\
\text { leader related to the research of the group }\end{array}$ & $\begin{array}{l}\text { Only the faculty member/teacher works as the leader } \\
\text { of the group and s/he has the responsibility to provide } \\
\text { directions to the team members }\end{array}$ \\
\hline Tasks & $\begin{array}{l}\text { The progress of the entire team's assignment concerns } \\
\text { every member in the team }\end{array}$ & $\begin{array}{l}\text { Each member in the team is focus only on his/her } \\
\text { components in the assignment where s/he is concerned } \\
\text { only about his/her components progress. }\end{array}$ \\
\hline Participation & $\begin{array}{l}\text { Teams are heterogeneous and have a diversity } \\
\text { membership }\end{array}$ & $\begin{array}{l}\text { Homogeneous teams are created (e.g., Teams are } \\
\text { created with graduate students of a similar rank) }\end{array}$ \\
\hline Skills & $\begin{array}{l}\text { Technical, research and professional skills are } \\
\text { assured and taught }\end{array}$ & $\begin{array}{l}\text { Members will only be taught 'necessary' research and } \\
\text { technical skills }\end{array}$ \\
\hline Development & $\begin{array}{l}\text { Members develop professional skills through } \\
\text { structured activities }\end{array}$ & They assume that members have professional skills \\
\hline Environment & $\begin{array}{l}\text { The cooperative environment is an integral part of the } \\
\text { model, encouraged and developed }\end{array}$ & $\begin{array}{l}\text { Research leaders control the environment which can } \\
\text { be highly competitive }\end{array}$ \\
\hline Improvement & The model includes process improvement & Improvement in process is not practiced nor is it ad-hoc \\
\hline
\end{tabular}


The CVEs where developed and mostly used in an educational region (beside to different regions) because it provides a fertile application terrain for it (Sandoval et al., 2020; Khalid et al., 2020; Al-Jarrah and Pontelli, 2016; 2020). The author (Liebregt, 2005) discussed six different CVEs, where he found that the CVEs were developed and mostly used in an educational region because it provides an fertile application terrain for it (Al-Jarrah and Pontelli, 2014). Moreover, he found that a number of advantages were provided by CVEs:

- The social awareness was supported by CVEs for university students

- The discussion possibilities and communications were improved in a wide scale

- Supporting constructivist learning in different subjects targeting different age groups

- Increasing the available information to the users

- Motivate the knowledge through collaborative creation

- Using different learning strategies makes the difficult concepts available via the virtual experience

\section{The Theory behind the Model}

The collaborative learning technology developed in the last decade very fast. A number of learning media and learning environments flourished to support the learning process with the required technology to enhance the learning outcomes and facilitate the learning process. Learning over a distance which is supported by collaborative virtual environments doesn't need students to be met face-to-face. The main requirements for the development of such environments are the enhancements of communication and the community of learning over distance. These types of developments are considered as a good alternative technique for learning in the classroom. The developed virtual learning environments support teachers and students with all required components as described in the modern of pedagogies.

As we mentioned, most of the students have an account on one or more social media channels, such as; Facebook, Twitter, WhatsApp, Instagram, etc. They benefit from using social media for looking for information, get help, communicate with classmates, etc. In this study, we studied the different types of social media usages by Ajloun university college students. In this study we focus on the use of social media by computer science and mathematics students. More specifically, we manage and control groups for introductory programming courses with the context of using the ARG model. Initially, the ARG model was used mainly to help undergraduate students to work together face-to-face on a common research problem. We extended the model to be used by students to collaborate together to learn over distance using one or more social media channels. We established a new model and called it "Learning Programming in Social
Environments within Affinity Group (LPSEAG)" that can be defined as; a learning methodology for students learning programming in introductory computer programming in collaborative affinity groups through social media.

The core idea of the model is to enable collaborative learning over distance using available media in the context of ARG. Each member in the group collaborates and interacts with each other throughout the learning material. In the assignment, each member recognizes that the success of the whole group requires a full contribution by each member and each contribution is essential for the group's success. Moreover, the failure means not only the failure of an individual member but the entire group. LPSEAG model manages and controls a group of students to support the process of learning for programming language in social using available social media. It allows the group members to collaborate, communicate and transfer information and knowledge between students and instructors.

\section{Social Media as an Environment for Implementing LPSEAG}

Social media is an environment that team members work together to accomplish the common task. In each section of the chosen courses, students are divided into sub-groups. Each sub-group creates a private social media group to work together on the common task. The created group over social media facilitates the group collaboration to solve the assigned problem. Each subgroup collaborates over distance using social media group as the following:

1. ARG model are met: Team members follow the extended ARG model to ensure that each member completes their tasks as required. The requirements of LPSEAG as an extension of ARG with the relation of each feature provided by social media are discussed in details in section 3.2.1

2. Discussions: Each member shares his/her ideas about the task over the social media group. It allows the member to collect feedback from other members about his idea and how s/he can finish his part in the deadline. For example, Facebook allows other members to write a comments on the posted idea and have a discussion about everything in details. The comment can be any type (e.g., text, image, video, sound, etc.). Moreover, the post can be a question and the member collect other members answers which help him/her to achieve his/her task at the time

3. Meetings: One of major requirements in the model for the group is to schedule meetings different types. Social media provide a required feature for the team members to meet and have a discussion synchronously about their task. The type of meeting 
and their requirements are discussed later in section 3.2.1

4. Collaboration requirement: Later in section 3.2.2, we discuss the five main components of collaboration, team members use the social media to ensure that the five components are met. The success of the group requires the components to be implemented carefully through the team work

In next sections, we discuss the LPSEAG components and in each component we mention the required feature of social media to make sure that the model is implemented successfully.

\section{LPSEAG Model Components}

The proposed model is based on the principal and dynamics of combining components of the ARG model principal with the five elements of collaboration. Therefore, the new model extends the essential of the ARG model principal to enhance learning programming in social. On the other side, the success of the LPSEAG model depends on how the elements of collaboration are implemented.

\section{Principal ARG Components}

The LPSEAG model extends the ARG components to increase and enhance the benefit from letting students learn programming in CVE in groups. The ARG model was built on three essential elements; Students connectedness, core purpose and management scheme. These three elements were mapped directly into LPSEAG.

It is important to declare the reason for establishing the team, which is declared in the definition of core purpose in ARG. In the first-class of each of the selected courses (ARG refers to it as an orientation phase), the instructor declares the core purpose for each team (Kephart and Villa, 2008). Moreover, each team will have a clear vision about the team activities and planning; defines the method that they will use to assess progress for each given assignment over the semester. In the given collaborative work, the group of students has a common goal that needs to be achieved within the deadline of the given assignment. According to these definitions, the core purpose can be mentioned as the inspiration for the team to work together and as a guide to achieve the common goal (Al-Jarrah and Pontelli, 2020; 2016; 2014; Al-Jarrah, 2016). Student success, cooperation and excellence are the three core values of ARG (Gates et al., 2008) that are adopted by LPSEAG.

In each selected course, students have a number of different programming assignments. Each team has to work together on the given task to gain different types of programming skills and experiences. In the orientation phase, the instructor (as the supervisor of each group) asks students to answer a pre-survey about students' backgrounds and makes a class discussion to collect information about students' concerns and perspectives. It is a new environment for students to work in a group to solve a programming task, they don't have any idea how to collaborate as a team to achieve the common goal, therefore, the instructor's role is to declare the required steps to solve each task in details as a team and the role for each member attached with the task part. The lifetime for each assignment could be one week or two according to the number of work required in the assignment.

In the proposed model, social media is used as an environment for collaboration by each team. The team management should be clear for each member of the team and it should be defined as an important component of LPSEAG. The group member with the instructor use LPSEAG to determine the required steps to do each task, define the task parts and map each part with the task timeline. Moreover, the LPSEAG defines the required work in each part tied with the method of using social media to facilitate the collaboration in the group. The work of the team under the support of the LPSEAG model should be mentored as:

1. Assignment stages should be determined carefully within the timeline for each stage

2. All information about assignment progress should be collected by the system. It contains information about each sent and received message, sender and receiver name, type of help required, feedback about the problem, etc.

3. At the beginning of each assignment, the member roles are assigned and can be changed within the lifetime of the assignment. For example, roles can be assigned using any of these techniques; randomly, votes, by a supervisor, selected by members, etc.

4. The supervisor uses the collected data to evaluate each member's contribution in the work and to evaluate the work progress based on the assignment timeline. The information can benefit students to encourage each other, decide about assigned roles and if they want to change it and to have a group discussion about challenges and how to collaborate together to resolve it

Each assignment is divided into parts that can be finished in level phases; each phase should be finished in a specific time. Moreover, at the end of each phase, there are expected deliverables which should be defined clearly at the beginning of the task. Task analysis, design, implementation and testing are common phases. The team members' roles are changed at the end of each phase to allow students to practice on a different type of collaboration in the team. At the end of each phase, the expected deliverables submission is defined as the leaders responsibility. Moreover, at the end of each assignment, students should submit the final version of work for the 
supervisor. The final submission is a part of the group leader's mission, where it should be done after all members have an agreement about the final version. The timekeeper keeps alerting the team about the deadline for each phase, the whole task and the project to have the final submission.

Programming in social required the instructor to have clear instructions about essential activities for each task and project. In LPSEAG, activities are essential components that should be structured carefully to be suitable for social media environments. Meetings are the other important component that should be scheduled and organized to allow team members to work together on the common problem in synchronous mode.

\section{Five Elements of Collaboration}

The proposed model (LPSEAG) is established based on the five elements of collaboration as elementary requirements to manage and control the work of the group members (Felder and Brent, 2007; Gates et al., 2008). It is essential to have clear criterion to evaluate the team work and ensure that the group's goals are achieved. The five elements are enhanced to be suitable for LPSEAG model which make them good to be used with social media. Moreover, the five elements of collaboration are enhanced to merge with the ARG model in the LPSEAG model. The following presents how each of the five elements is captured in LPSEAG.

\section{Positive interdependence:}

This principle is very important to define clearly each member's responsibilities. Each member should understand that his/her contributions are essential and important for the whole team. On the other side, the member's failure in doing his/her duties means the failure of the whole team. The scope of responsibilities for each individual team member is determined by the given role as the ARG model defined. At the beginning of each assignment, roles are assigned and revised during the different phases of the task. Each role defines what each member should do and when s/he has to do.

To support members, we built an application with different features and capabilities that can be used by members to collect data (explained in details section 4). For example, a timekeeper records the time spent on each part of the task to monitor the work progress towards the common goal, a note-taker collects notes from members and shares them on the used social media, records ideas from the group discussion and meetings to record the contribution of each member. A set of metrics are set to evaluate each member's contributions and the performance of the overall team. Also, the metrics are used by the supervisor to evaluate individual contribution and by the team leader to assess the overall progress.

2. Face-to-face promotive interaction:

The model should provide suitable learning environments that support the team to work together over distance as they work together face-to-face. Social media provides a channel for members to share information, experience, skills, etc. and they communicate to encourage each other to spend more effort in learning. Social media, in general, provides different types of communication channels. Moreover, members can broadcast different types of files over social media and it could be used as a shared workspace to put all shared, information, announcements, etc. that can be used by the team at any time.

LPSEAG model takes advantages of social media to organize different types of meetings that support students' interactions: Orientations, team meetings and task meetings. At the beginning of each course, an orientation meeting is held to familiarize students with the requirements to collaborate together as a team to solve the common tasks. In the team meeting, each team has a conversation to have a discussion about everything related to the task. Moreover, the team meeting is a good space for members to encourage each other and discuss the group's progress. At the end of each assignment, all groups come together to discuss their achievements and solutions and share ideas about the problems that they faced and how they solved them.

3. Individual group accountability:

The individual contribution is essential for the team to achieve a common goal. According to this, LPSEAG provides assessment criteria to assess work progress and individual performance. The supervisor and the group leader can review the collected data which reflects each member's contribution.

4. Professional skills:

The proposed model supports the team members to gain good skills for working as a team. Students also learn problem-solving as they work together as a team. Social media supported by the LPSEAG model presents required features to scaffold the development professional skills, such as communication skills, notetaking, time management, accountability and critique.

5. Team processing:

The responsibility of the members is to make a decision on how to achieve the common goals of the team. Assigning roles and duties is a fundamental basis of team processing. The roles and duties are dynamics; therefore, they are a core component of 
team processing activities. The change of roles and duties can happen during task phases in the team meeting.

\section{Member Roles}

LPSEAG model imports suitable roles from the ARG model. Gates et al. (2008) define three categories of roles; support group functions, help the team formulate information and help the team ferment ideas and resolve conflicts. In addition to the transferred roles from ARG, (Al-Jarrah and Pontelli, 2020) define a number of roles in Collaborative Virtual Affinity Group (CVAG) model that forms a good practice for students for learning programming. Based on the defined roles, students can practice on solving programming problems from problem understanding and analysis level to deliver the final version of the software level. Table 2 presents the roles that are transferred from the ARG and CVAG models to LPSEAG model.

Roles are assigned at the beginning of each task by the instructor randomly. Students dynamically switch between roles. Moreover, LPSEAG allows one role to be held by more than one member at the same time; for example, the team can have more than one author at the same time as the current phase requires. Also, a member can hold more than one role at the same time, e.g., the leader can be a time-keeper, an author, note-taker while $\mathrm{s} / \mathrm{he}$ is the group leader. The roles are changed dynamically within the work progress which allows students to practice on different types of skills and gain a different type of experience as they work collaboratively on the common task. At any time, the model allows students to choose what role they act. This type of dynamic assignment and changes of roles adds a significant value on the learning output; (1) It enables students to practice acting all the roles and gain experience and skills on different duties and activities. (2) In the case where more than one student has the same role at the same time, which allows exchanging experience and sharing information among students.

\section{The Distributed Application as a Utility Tool for Study Purposes}

For study purpose, we create an application to be used by the instructor and students to collect information which we called Collaborative Application for Programming in Social (CAPS). CAPS is a collaborative virtual environment that contains a shared work space for team members and instructors. The overall architecture of CAPS is standard client-server architecture (Fig. 1). CAPS is used by all teams; teams that follow LPSEAG model and teams that work without follow LPSEAG. When the team follow LPSEAG model, the enabled features will be according to the user role-section 4.2.2 shows the main features for some roles and how could be used for other teams that doesn't follow LPSEAG.

Table 2: LPSEAG roles' definition in addition to the imported roles from ARG and CVAG.

\begin{tabular}{|c|c|c|c|}
\hline Role & ARG* & $\mathrm{CVAG}^{* *}$ & Definition \\
\hline Author (driver) & No & Yes & $\begin{array}{l}\text { Write the real codes by translating the created design in design phase. S/he has to be familiar } \\
\text { with the language statements of the programming language that the team practices on. }\end{array}$ \\
\hline \multirow[t]{2}{*}{ Leader } & No & Yes & The leader has the following responsibilities: \\
\hline & & & $\begin{array}{l}\text { - Assign roles to the team members, } \\
\text { - Change roles if required while they work on the task, } \\
\text { - Submit the final version after it has been agreed on from all team members, } \\
\text { - Share ideas about members' contributions, } \\
\text { - Encourage each member to do his/her duties and } \\
\text { - Encourage the team to finish on time. }\end{array}$ \\
\hline Analyzer & No & Yes & $\begin{array}{l}\text { In the analysis phase, the analyzer has the responsibility of analyzing the problem } \\
\text { requirements; define input, required processing and outputs. }\end{array}$ \\
\hline Designer & No & Yes & $\begin{array}{l}\text { Designs the algorithm, designs the use-cases and defines the time-line activities and events } \\
\text { of the program. }\end{array}$ \\
\hline Time keeper & No & Yes & $\begin{array}{l}\text { Records the time for work progress, determines the required time for each subtask and notifies } \\
\text { members. Time keeper notifies members of the deadline to finish each subtask and the time to } \\
\text { switch roles. }\end{array}$ \\
\hline Explainer & Yes & Yes & Receives feedback from members and shares ideas and opinions. \\
\hline Clarifier/paraphraser & Yes & Yes & Receives feedback from members and clarify a message. \\
\hline Idea criticizer & Yes & No & $\begin{array}{l}\text { Challenges group members intellectually by criticizing their ideas while expressing respect for } \\
\text { them as individuals. }\end{array}$ \\
\hline $\begin{array}{l}\text { Accuracy } \\
\text { coach (Navigator) }\end{array}$ & Yes & Yes & $\begin{array}{l}\text { Reviews the overall written code and the logic structure of the code, reads the written codes by } \\
\text { looking for errors and looks for required information and brainstorms with the team. }\end{array}$ \\
\hline Integrator & Yes & Yes & $\begin{array}{l}\text { Integrates all collected ideas from members and puts them all together into one place that each } \\
\text { member can access and all member can agree on. }\end{array}$ \\
\hline
\end{tabular}

* ARG (Gates et al., 2008)

** CVAG (Al-Jarrah and Pontelli, 2020) 


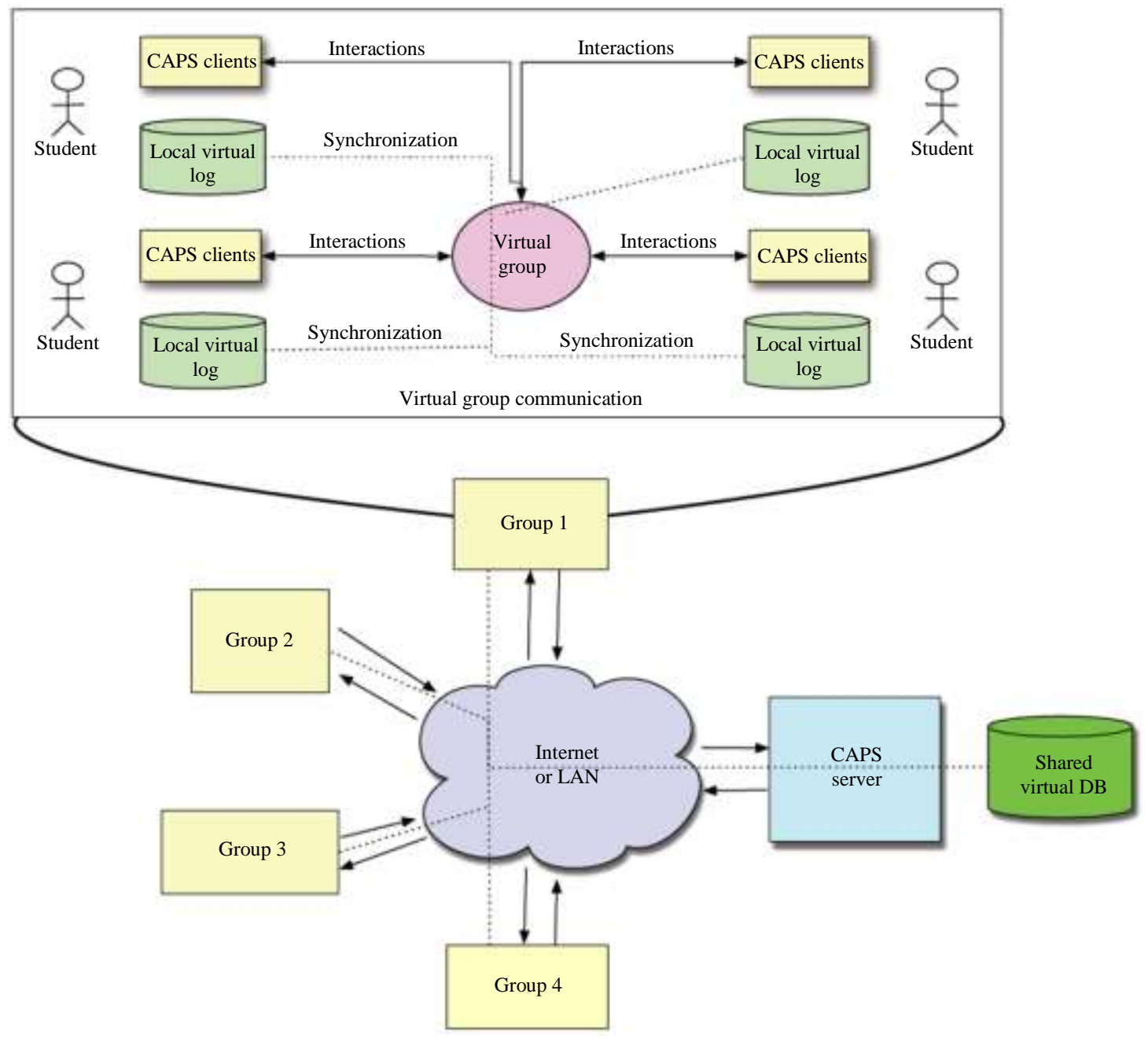

Fig. 1: The overall architecture of CAPS

\section{Users' Information and Transaction Log}

The application allows the instructor to create teams with assigned students. Therefore, the application maintains a database (using XML format) that stores students' information, such as; name, nickname, password, roles. The database stored at server side. When the user try to access the system, it asks him/her to enter his/her user name and password, the client sends a login request to the server; the server check the received data from the client and returns an acknowledgment with student's information.

The instructor also creates project with details, such as; name, deadline, description, required phases, etc. The project information is also stored in the database. when the student logged to the system, the server return the attached project to the student with the current state. Not only that, but also the database contains all transactions that are made by students. When a transaction is made by a student, it is stored in a local XML file and broadcast a copy to other team members, as well as the instructor and the server.

\section{Graphical user Interface}

The graphical user interface of CAPS is created to enable access to the features that support LPSEAG model and provide the required features for team members. Each feature provides a friendly graphical user interface for a member with a specific role.

At the beginning, the interface in Fig. 2a appears for the student and ask him/her to login to proceed. After student hit login button, the login window (Fig. 2b) appears which asks student to enter his/her username and password. After the student logs in to the system, the student information is loaded, such as; name, role, group members, project info, etc. and enables the appropriate features based on his/her role.

The main interface consists of five tabs; welcome, instructor's features, students' features, white board and help. The features in 'instructor's features' and 'students' 
features' tabs will be enabled according to the role of the logged user. For example: In case where the logged user is an instructor, the features in the second tab are enabled as in Fig. 3.

\section{Instructor Features}

Figure 3 shows the basic features that support the instructor work:

1. User profile: This feature allows the instructor to show his basic information and change his/her password

2. Students: When the instructor hit the student's button, a new window appears with a list of students. In the new window, the instructor can show students information in detail. Moreover, the instructor can modify student information, add new student, or delete student from the list. furthermore, the instructor can review the students in each team as in Fig. 4 which shows the first student's information in the team

3. Groups: This feature allows the instructor to create a team, assign students to teams and delete a team

4. Transaction log: This is a very important feature for the instructor. All transactions that are made by groups' members are stored in the log file. The instructor can preview a table of all transactions by students. The instructor can show the team members contributions for different types of transactions. Figure 5 shows contributions for team members in the three different phases of task 1



(a)

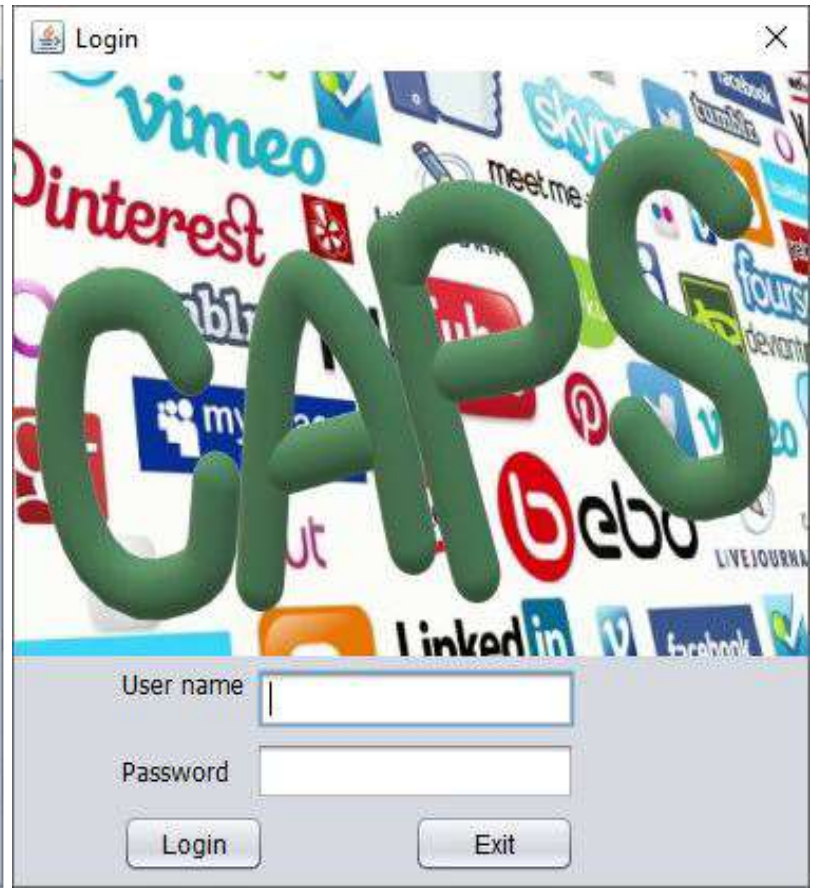

(b)

Fig. 2: The graphical user interface for CAPS; (a) The main user graphical interface. (b) login user interface

\begin{tabular}{|c|c|c|c|c|}
\hline \multicolumn{3}{|c|}{ (g) CAPS Application } & \multicolumn{2}{|l|}{$\square$} \\
\hline Welcome & Instructor's Features & Students' Features & White board & Help \\
\hline \multicolumn{5}{|l|}{ Features } \\
\hline & User Profile & \multicolumn{3}{|c|}{ Students } \\
\hline & Groups & \multicolumn{3}{|c|}{ Transaction logs } \\
\hline
\end{tabular}

Fig. 3: The basic instructor features 


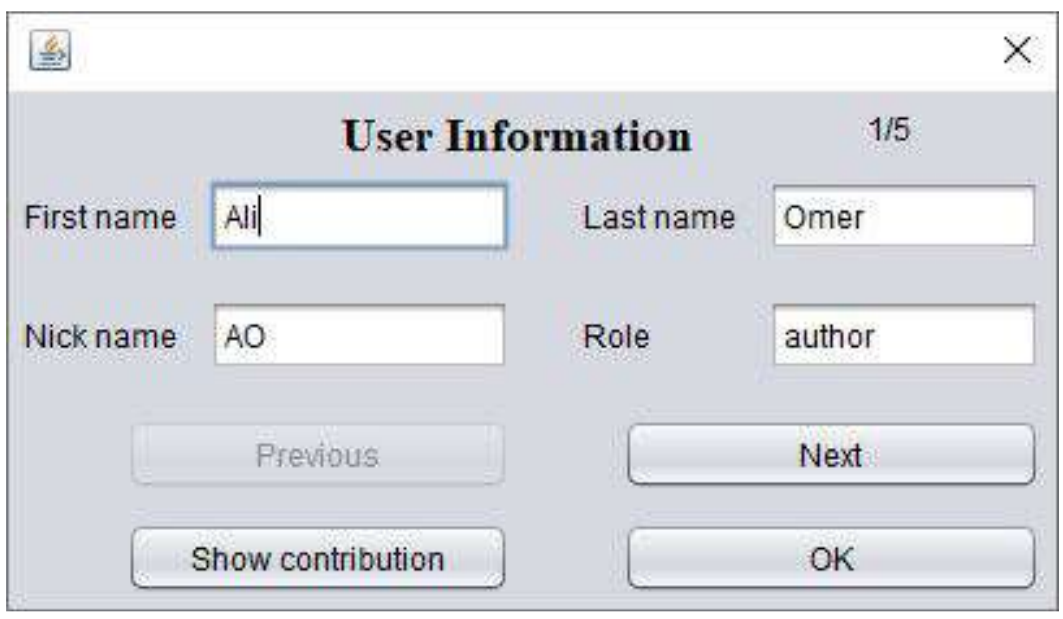

Fig. 4: The user information with the ability to browse the student's contribution



Fig. 5: The basic instructor features

\section{Different Features for the Members' Roles}

The third tab in the main user interface consists of team members' features. After the student logged into the system, his/her information will be loaded from the server which contains the member role. Based on the member role, the system enables the appropriate features. In case the student acts as more than one role at the same time, the system will enable all features for each role:

- Leader features: The main responsibilities of the group leader manage and control the group. Therefore, s/he can review member information and review the contribution of each member (Fig. 6). Moreover, the leader can manage members' roles at any time. As in the Fig. 6, the leader can allow the member to change his/her role by checking the check box beside the member, or prevent his/her by removing the check. The leader reviews the work progress over the time. S/he uses the groups on social media to communicate and publish information that encourages members to work. Moreover, the instructor has the responsibility to submit the deliverable after the team finishes the required work at the end of each phase

- Author features: The author has the responsibility for writing the required code in the used programming language (e.g., C++, Java, Python, etc.). S/he has the ability to translate the created design (algorithm in the 
design phase) into programming statements. Therefore, the author needs a TODO list which contains a list of tasks that s/he should finish in the limited time. Figure 7a has the task's list which allows the author to keep track of completed tasks, add a new task, store tasks' list, etc. The list of tasks stored in a data base file (an XML file). The database is created at the server side, which allows the author to follow up with his/her work on any machine that has the CAPS application (e.g., any computer at the university lab or at home). Also, the database can be transferred to any other author when switching roles to complete the work

- Navigator features: The core responsibility of accuracy coach (or known as navigator) is to support the work of the author. S/he works on finding necessary information with the group to solve the faced challenges. Furthermore, the navigator brainstorms to challenge the group members for finding the appropriate ideas on how to solve the task/sub-task. The second mission for the navigator is to think about the overall structure, find any appropriate enhancements that can be implemented on the structure of the code and identify if there is any probable bugs. Finally, the navigator has to review the code by looking for errors. S/he reviews the developed code and adds required comments which can form questions about the code for the author specifically and other team members to think about possible enhancement(s) on the code. Figure $7 \mathrm{~b}$ shows the navigator features which allow him/her to create a list of tasks to organize his/her work. The same as the author features, s/he can save the task's list, restore it from the server, create a new task, etc. Also, the task's list can be transferred between members in case the team has more than one navigator or the navigator role is assigned to another member

- Time-keeper: The main responsibility for the timekeeper is to monitor the time and make sure that team work progress based on the timeline created at the beginning of the project. Figure 8 show that the time-keeper can make a list of tasks attached with the member that is required to finish it at a specific time. When the member finishes the task, the timekeeper puts a check beside the task which means that the task is finished. S/he has to communicate with team members through social media to discuss with them about each task and the required time and s/he needs to announce the remaining time for each task to challenge the team to finish in the deadline

In case that the team doesn't follow the LPSEAG mode which means that there are no roles, the provided features will be available to collect information from students, such as:

- Each member needs to start a timer to count the spent time working on each part. This feature is important to measure the average time that each team spent working on the assignment

- Statistics about transferred messages between members over used social media. The instructor can categorize messages into different types; questions, answers, feedback, information, correctness, etc.

- The number of errors; syntax, logic, fatal, etc. that appeared at the end of each phase

- The amount of code and the solved part by each member. Which helps the instructor to evaluate each member's contribution

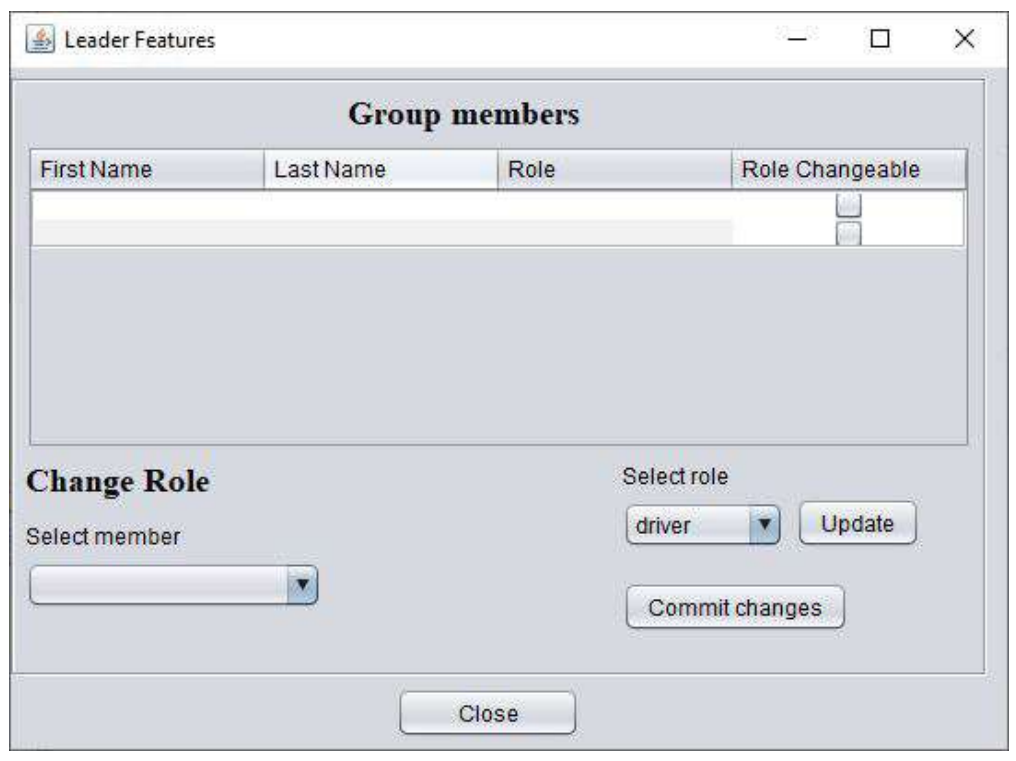

Fig. 6: The basic leader features 


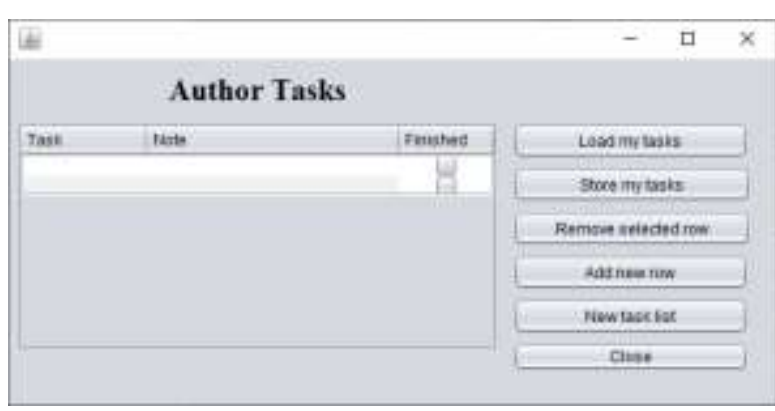

(a)

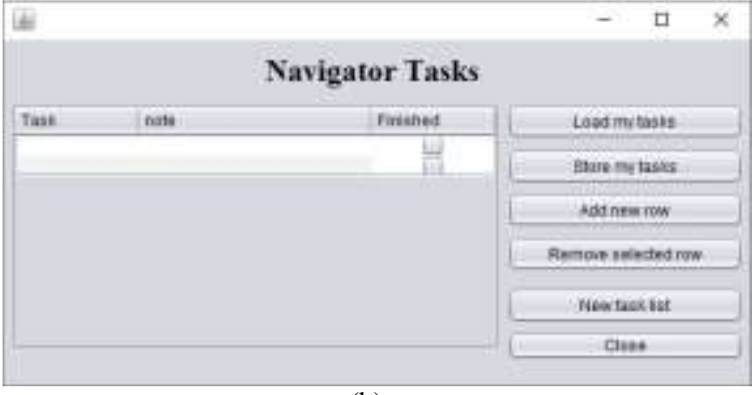

(b)

Fig. 7: The main features for author and navigator roles. (a) The main user graphical interface. (b) Login user interface

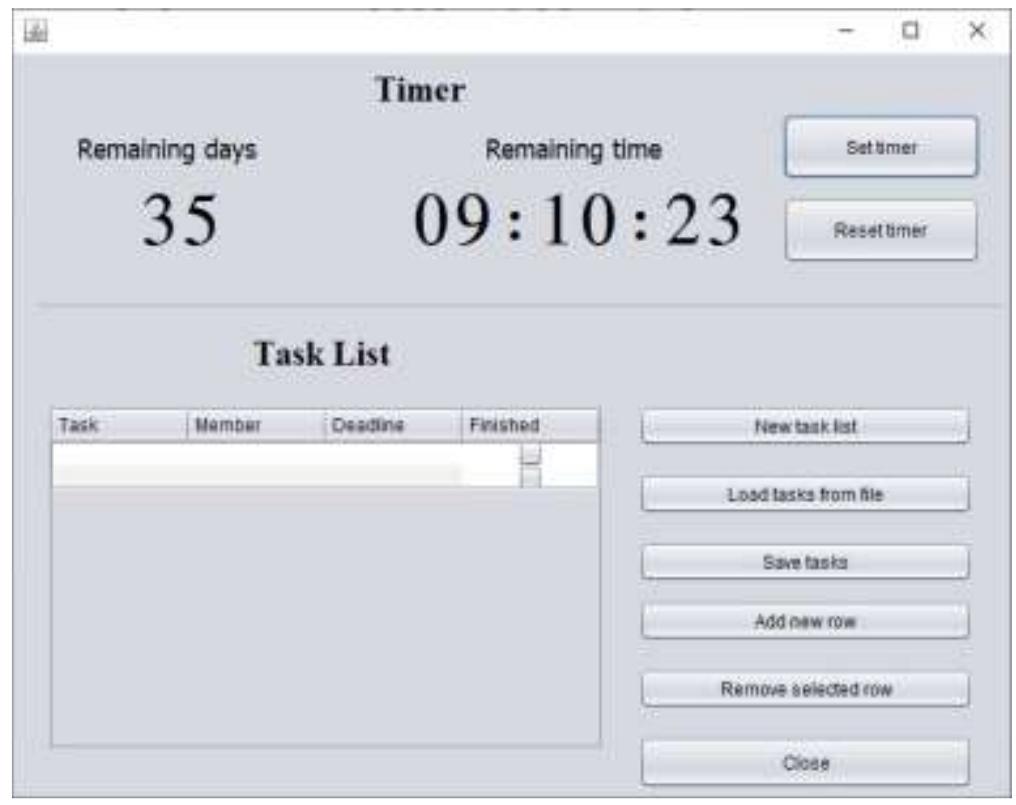

Fig. 8: The main feature for time-keeper role

\section{Application-Level Communication Mechanism}

CAPS is a collaborative virtual environment that provides a synchronous view of shared information about team members' contributions. Regardless of the team members physical location, members are connected through the internet. According to the requirements of the communication layer that supports the exchange of data among remote members, RabbitMQ (2015) is a message brokering which provides a transferring mechanism of information between users. RabbitMQ is implemented based on Advanced Message Queuing Protocol (AMQP). RabbitMQ is an open source, where it is a suitable protocol for transferring data as required by CAPS. The protocol provides a reliable technique for transferring messages. Exchange message queues are created to connect team members sessions. It uses a fan-out exchange out which enables a team member to broadcast messages to other members. The sent data is stored at the administrator's side (e.g., instructor or supervisor) in a log file and at members' sides.

\section{LPSEAG Model Evaluation}

\section{Hypotheses}

Three hypotheses was tested in this study to evaluate the effectiveness of using LPSEAG model in learning programming:

1. The first hypothesis is that creating a model for learning programming using social media (LPSEAG) - that consists of extended ARG model - makes the virtual learning environment more effective and suitable for a team to collaborate over distance

2. The second hypothesis is that the usage of social media as a collaborative virtual environment for learning programming as monitored by the instructor increases the learning outcomes and enhances the learning environments

3. The third hypothesis is that implementing the software development process in LPSEAG model makes learning programming more effective and usable for a team to collaborate over distance 


\section{Methodology}

We aim to evaluate the effect of using social media in education with the extension of the Affinity Research Group. For this purpose, we design assignments in each selected course (section 5.2.1). Each assignment is designed as a group assignment that students in each team have to collaborate while working together over distance to solve the shared assignment. In LPSEAG, each team creates a group on selected social media (Facebook and WhatsApp). They have to communicate together to make discussions, share information and transfer codes between team members using only the created groups. The other teams - that doesn't use LPSEAG model - have to work together to solve the assignment, but they don't follow the LPSEAG model and they use social media just in traditional use.

Students with a diversity of background as the presurvey showed in section 5.2.1 are assigned randomly to teams with 4-6 students each. Teams are divided into two categories in each course. Both categories use social media with ARG (LPSEAG model) and social media without ARG, alternating the two methods. Figure 9 shows the used methodology to evaluate the LPSEAG model. As it appears in the figure, each assignment is solved by all teams. Two assignments are solved before the midterm exam and the other two after it. Before the midterm exam, teams in the first category solve the first two assignments following LPSEAG where teams in the second category solve them without using LPSEAG. After the midterm, teams switch the usage of LPSEAG; teams in the first category solve assignment three and four without following LPSEAG and teams in the second category solve them following LPSEAG. Before the midterm, students in categories 1 fill post-survey 1 which is about the usage of LPSEAG, where students in category 2 fill post-survey 2 which is about solving the assignments in a traditional method without using LPSEAG. Before the final exam, students fill the two post-survey based on the used approach.

\section{Participants' Background}

The study targets undergraduate math students and computer science students. Computer skills (C++ programming), Java, object oriented programming and python courses' students are the main targets for this experiment. Computer skills course -where students learn $\mathrm{C}++$ programming - is the first programming course for undergraduate computer science and mathematics students at Al-Balqa Applied University. After finishing the computer skills course, CS students study the other two courses in order (Object Oriented Programming and Java programming language) and math students study Python programming language. We ran the experiment in the offered courses in the academic years 2018/2019 and 2019/2020. Table 3 shows the distribution of students over selected courses. The total number of students over the two academic years in all classes is 569. The sections of Java, OOP and Python are selected to have students that are not part of the study in previous semesters.

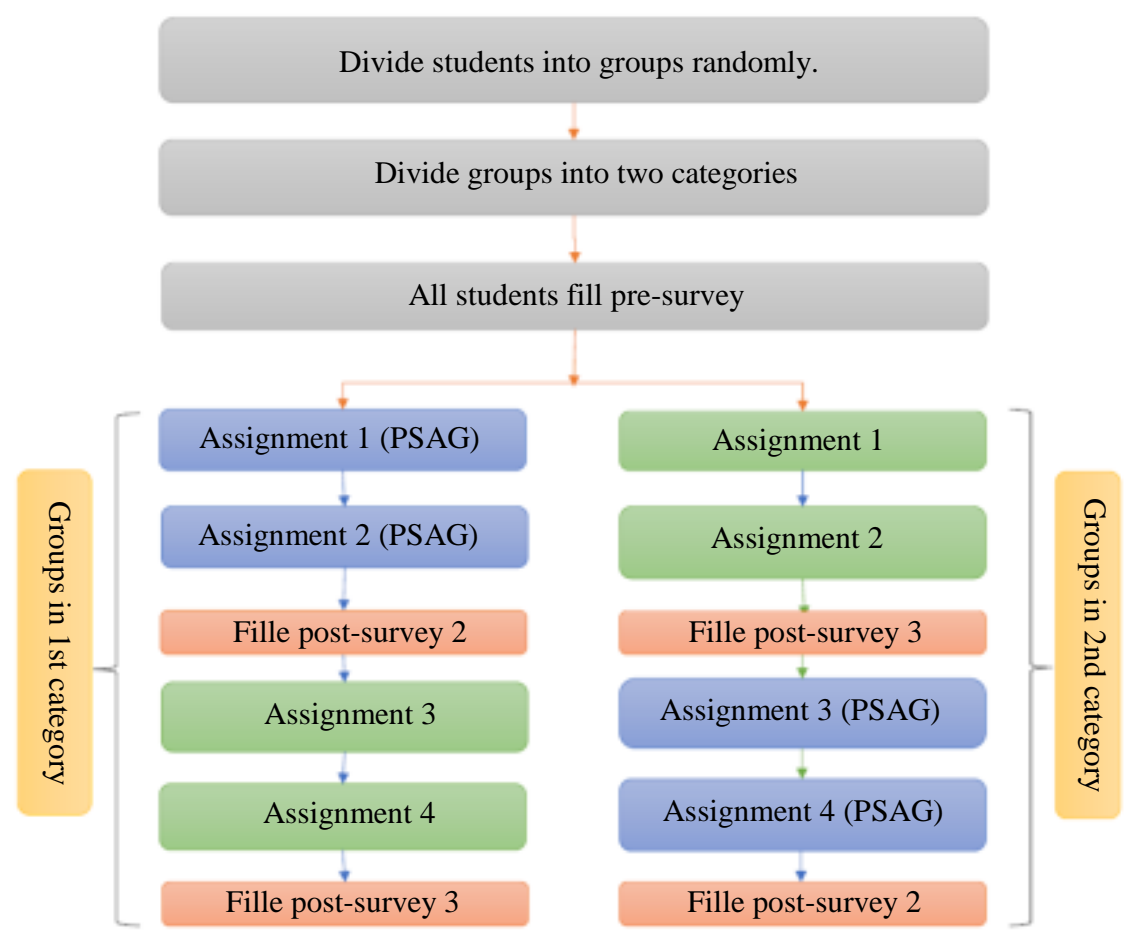

Fig. 9: The evaluation process 


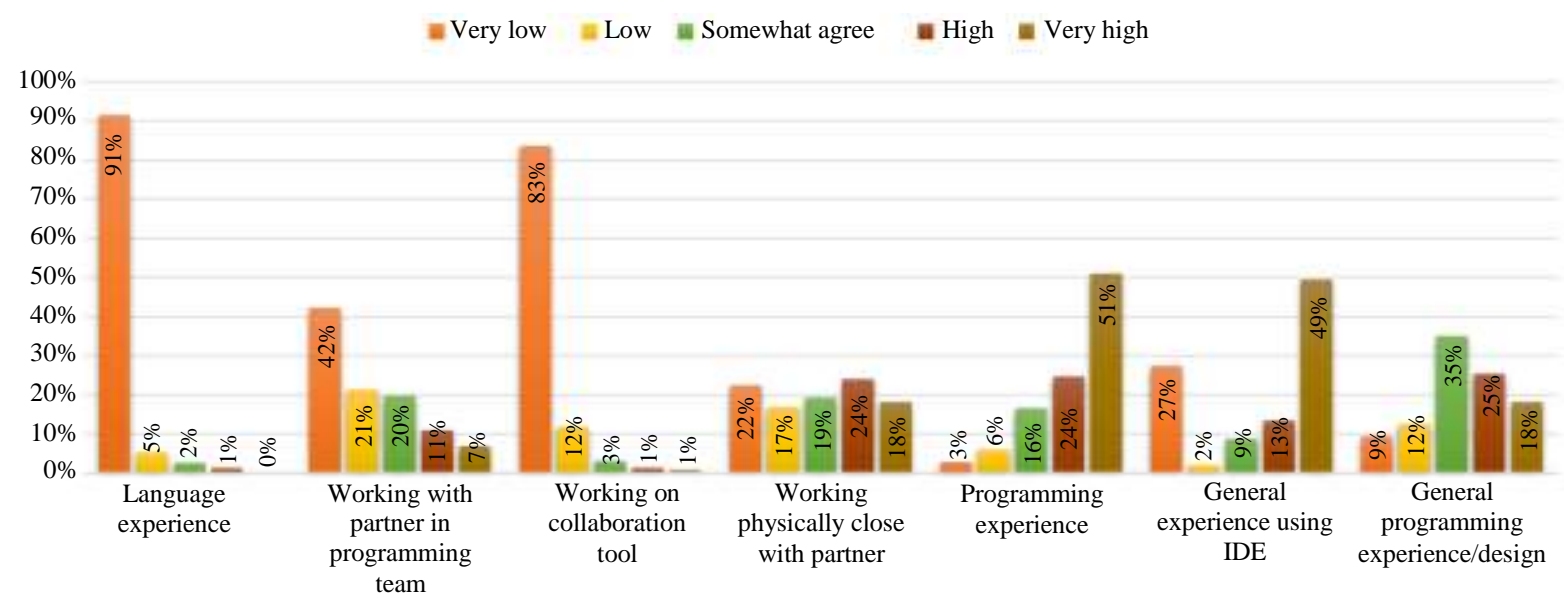

Fig. 10: The over all experience in the specific programming language, working on collaborative tools and working with a team

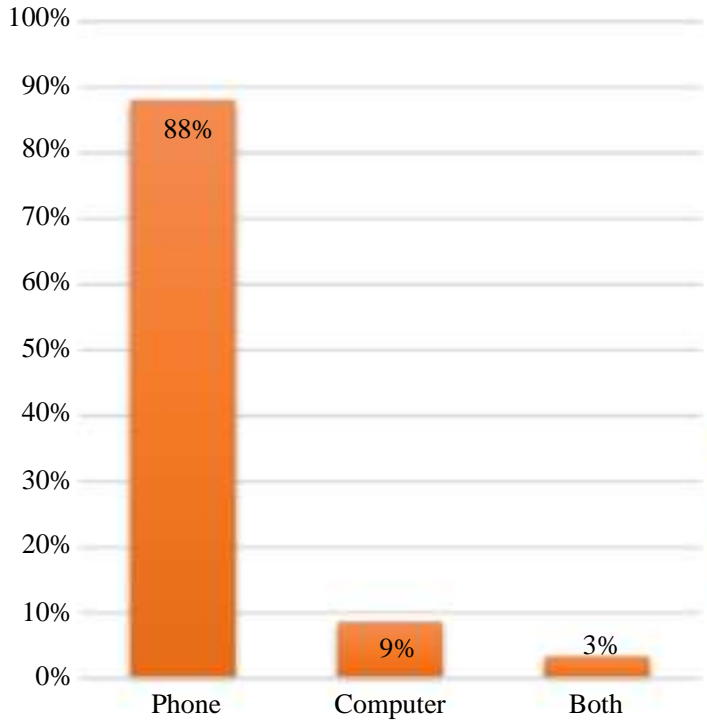

(a)
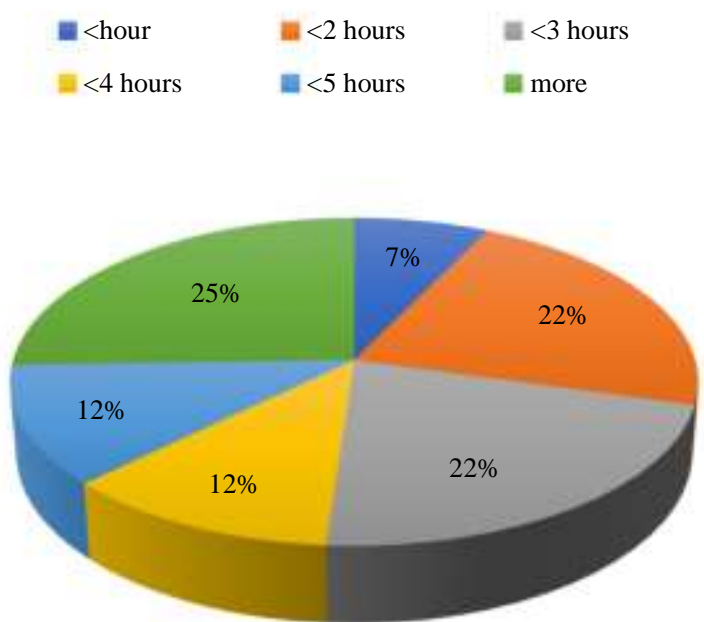

(b)

Fig. 11: The used devices to access social media and the average amount of time that students browse social media per day; (a) The used devices to access the social media; (b) The average amount of time that students browse social media per day

Table 3: Students' distribution in the selected courses

\begin{tabular}{ll}
\hline Courses & \# of students \\
\hline Computer Skills 2 (C++ programming) & 173 \\
Java Programming Language & 120 \\
Object Oriented Programming (OOP) & 153 \\
Introduction for Programming (Python Language) & 123 \\
Total & 569 \\
\hline
\end{tabular}

At the first lecture in each class, students filled a pre-survey, where it prepared to assess the student's background and programming skills. Each student has to rate him/herself on their programming knowledge and working in group experiences based on problemsolving. The collected data shows that the overall programming knowledge of students is very low.
Figure 10 shows the overall confidence for students in all related areas.

For additional information about students' usage of social media, the pre-survey contains different questions about different aspects of using social media by students, such as; how they access SM, the time spent on SM (Fig. 11), students' background about SM (Fig. 12a), types of SM's usage by students (Fig. 12b), SM affects (Fig. 12c), SM as an alternative learning environment (Fig. 12d).

\section{Questionnaire Design and Measures}

Students have been asked to answer a post-survey after working on assignments using each approach; 
LPSEAG and SM without ARG. The survey rates the used environment to solve the assignment. The two prepared surveys (post-survey 1 and post-survey 2) consist of questions where each question rates one aspect of computer programming and working on collaboration experiences. The aspects are rated on a Likert scale approach on five levels from 5 to 1 ('Strongly Agree' to 'Strongly disagree' consecutively). We rate working with a team without using LPSEAG model by post-survey 1 which includes the following points:

- Rate the overall experience

- Rate the effectiveness of using social media

- Rate the ease of communicating with your team

- Rate the level of satisfaction in each problem solving phase (Analysis, Design, Coding, Integrating, Testing)

- Rate the hardness of solving the assignments

- Rate the hardness working with a group over distance

- Rate the level of satisfaction for finding help

- Rate the speed to solve the problem

- Rate the time/efficiency consumed for communicating with your teammates

- Rate the probability of having errors and how many errors you have

- Rate the collaborative environment awareness

- Rate the fidelity of accessed information.

The post-survey 2 ranks the following points about working with a team using LPSEAG model:

- Rate the overall experience

- Rate the effectiveness of using social media with ARG (LPSEAG model)

- Rate the ease of communication with your team

- Rate the level of satisfaction in each problem solving phase (Analysis, Design, Coding, Integrating, Testing)
- Rate the hardness of solving the assignments using LPSEAG model

- Rate the hardness of using LPSEAG model to work with a group over distance

- $\quad$ Rate the level of satisfaction for finding help

- Rate the speed to solve the problem

- Rate the time/efficiency consumed to communication with your teammates

- Rate the probability of having errors and how many errors you have

- Rate the collaborative environment awareness

- Rate the fidelity of accessed information

The Descriptive Analysis of Students Responses

We analyzed the students' responses to the two postsurveys and discuss the students' behavior during assignments. To make sure that the comparison is fair enough when students answer the two surveys, they fill each of them in a switchable way; teams in the first category fill post-survey 1 first, then they fill post-survey 2 , where teams in the second category fill the post-survey 2 before post-survey 1 (Fig. 9). The following two subsections represent the student's responses for postsurvey 1 and post-survey 2 .

\section{Post-Survey 1: Using Social Media without LPSEAG Model}

Students were asked to work on the given assignments in teams. Each team has to use social media to collaborate without any rules to organize the collaboration and no roles for members. They have to use social media channels to communicate, discuss, share information, etc. After finishing the assignments, each student in the team has to fill post-survey 1. Questions in the survey assess the effectiveness of using social media in a traditional approach in a team to solve programming assignments. The following is the summarize of the outcome of the key questions in post-survey 1 .

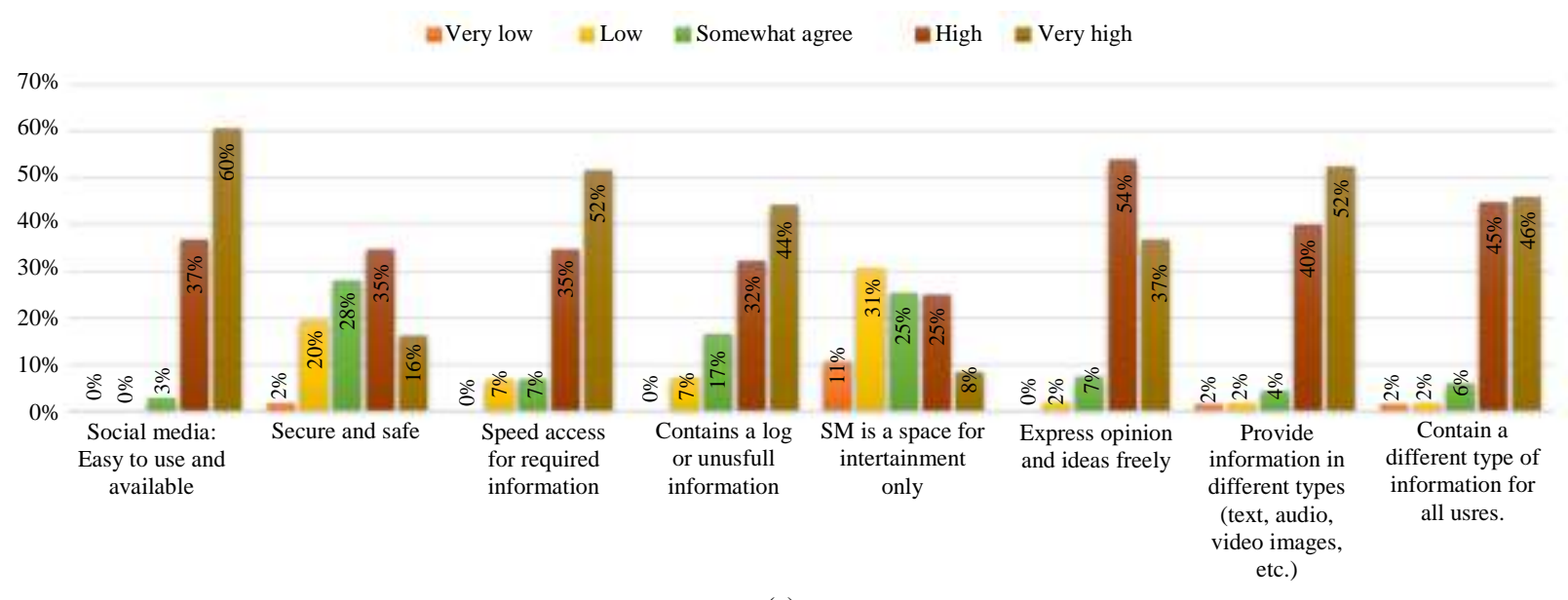

(a) 




(b)



(c)

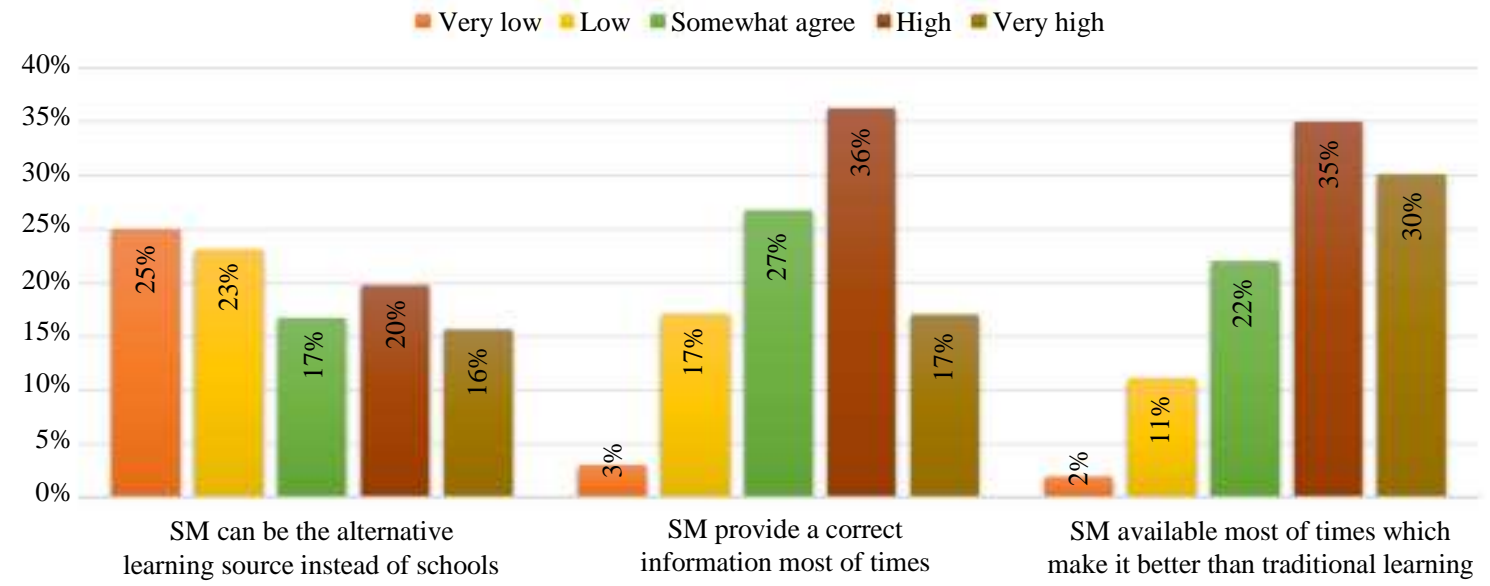

(d)

Fig. 12: The general aspects about students usage and what they are thinking about social media; (a) The students answers about social media in general; (b) The percentage of using social media by students in their study and it's affection; (c) The affection of social media on students; (d) The students responses about using social media as an alternative channel for learning 


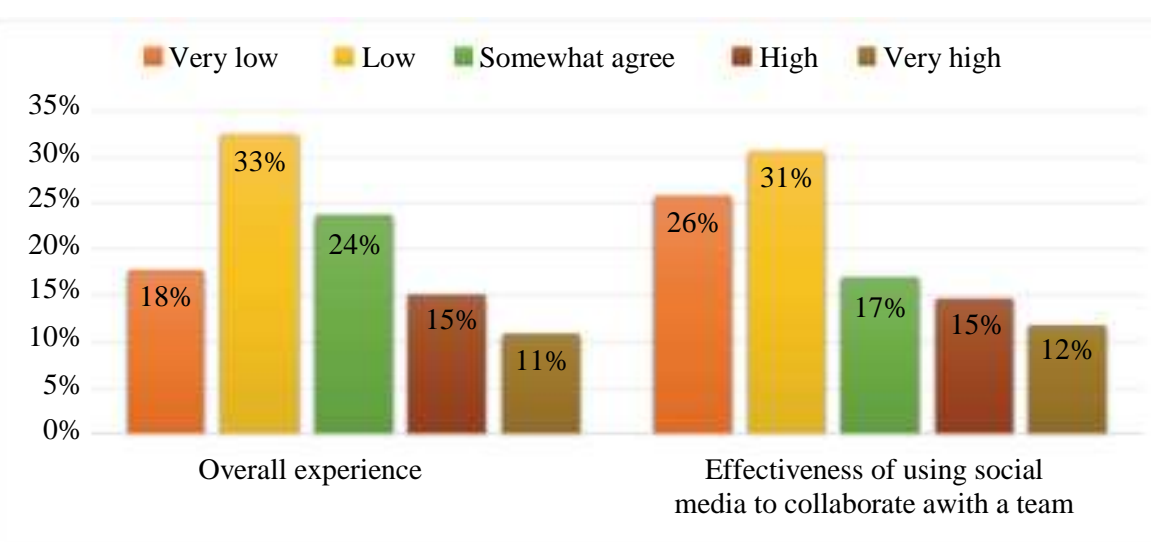

Fig. 13: The overall experience for students using social media without LPSEAG

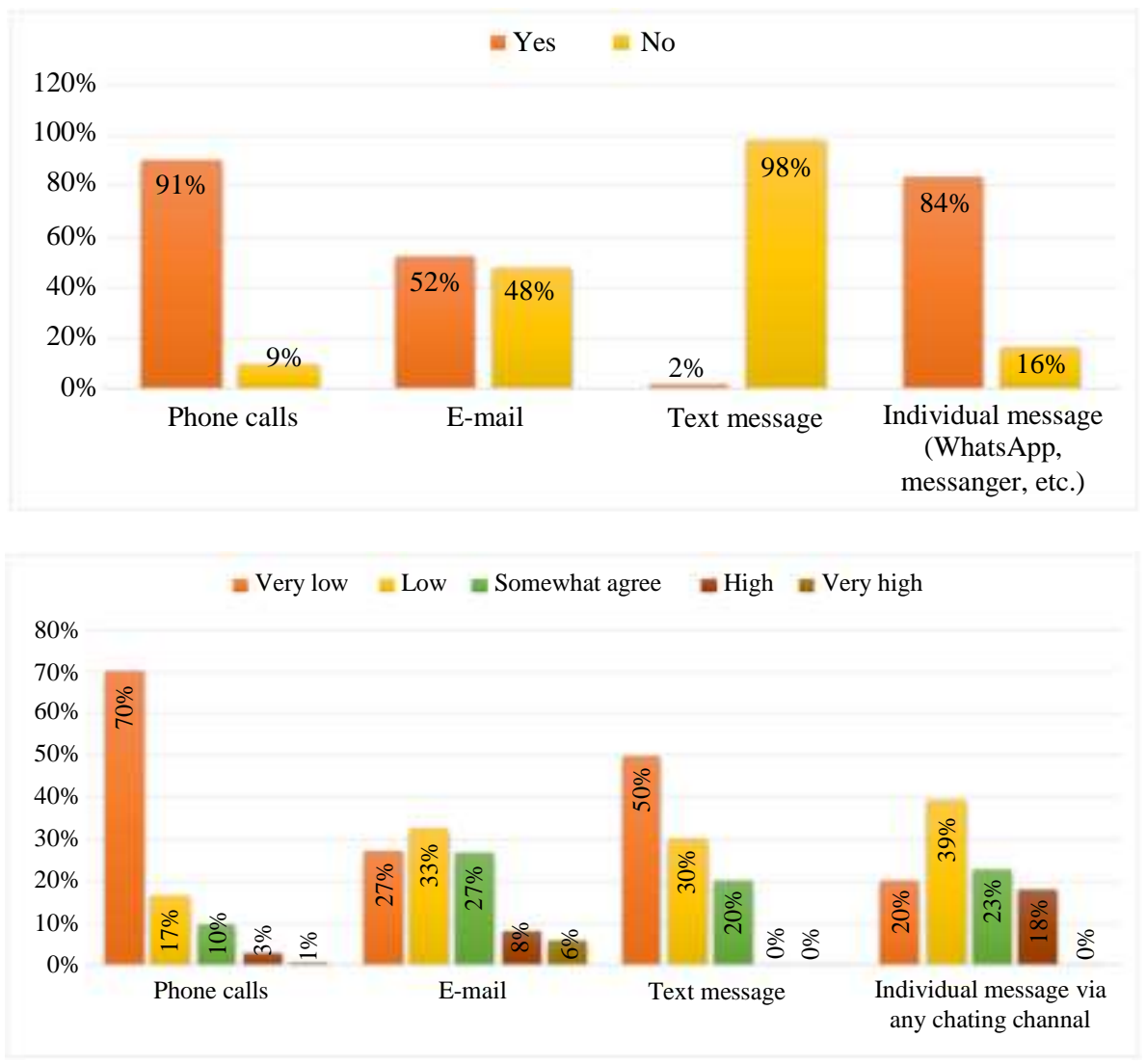

Fig. 14: The used communication channels on the left and the students satisfaction about the used channel on the right

We asked students about their overall experiences working with the group using social media only (Fig. 13). Students' responses show that $33 \%$ of students satisfaction is low and $18 \%$ is very low, where only $11 \%$ of students rank their satisfaction as very high. For more specific questions, we asked students to rank the effectiveness of using social media only to collaborate with a team to solve assignments. In Fig. 13, students' responses show that they rank the effectiveness of using social media as very low with $26 \%$ and low with $31 \%$ where only $27 \%$ in total rank it as high and very high. Therefore, students responses confirm that remote interaction using social media to solve group assignments is not an effective approach.

The second question asks students about the used media to communicate with team members (Fig. 14). Students' answers were limited to four types; phone calls, e-mails, text messages and individual messages via social 
media. They rank their satisfaction for each of the mentioned channels as following; they rank phone call as very low wit $70 \%$ of students, most of students with 27 and $33 \%$ rank the use of e-mail as very low and low, where just $6 \%$ of students are happy using email to communicate as a collaboration media. The students' satisfaction is the same thing for text messages and individual messages through social media where it appears as very low with high percentage of students. Students face a problem with communicating with team members to receive help in time, they rank their satisfaction about the hardness of using the communication media as very low (Fig. 15). Most of the students rank the communication as very difficult and difficult (26 and $33 \%$ consecutively), where only $8 \%$ of students rank it as very easy.

Figure 16 shows that students face challenges while they work on solving the common assignments as they collaborate together over distance. We can observe that a high percentage of students face difficulties of solving the given assignments. On the other side, $14 \%$ of students observed that it was easy to solve the assignments, but there aren't any students that rank working over distance with a group as very easy. Students highlight the problems that they face, we can summarize them as: (1) Because of bad communication between members, they can't share the right information they need, (2) They spent a lot of time waiting for help or responses from other team members for their requests. Therefore, Fig. 17 students rank the time spent looking for a help (feedback, question answer, etc.) as high more than low, where $48 \%$ rank it as a high level and $31 \%$ rank it as a low level.

Figure 18 shows the students' answers where they asked about their satisfaction of working on different programming phases. It is clear that students show a low satisfaction in the analysis and design phase. In the other threes phases, most students strongly disagree with working on theses phases with a group over distance, only $15 \%$ of students strongly agree on working on testing phase.

Students face difficulties working on solving problems, the effect of these difficulties appear clear in students' satisfaction of the speed in solving the problem (Fig. 19), where they rank it as low. Moreover, they rank the probability of errors occurring as high with $28 \%$ and very high with $22 \%$. The students satisfaction about communication reliability is moderated. Figure 20 focuses on the overall awareness which is related to what each member is doing and the comprehensive level of fidelity.

\section{Post-Survey 2: Using LPSEAG Model}

Each team has to solve two assignments using LPSEAG model. At the end of solving the two assignments, we asked students to answer a post-survey. The first question asked students to rank their overall satisfaction about solving the assignments using LPSEAG model. Figure 21 shows that $34 \%$ of students rank their overall responses as satisfactory, where students' experience is ranked as very low by only $12 \%$ of students. Moreover, students rank the effectiveness of using LPSEAG model with 50\% in total as high and very high, where the total responses that rank it as low and very low is $38 \%$, where $13 \%$ rank it as somewhat high. Students need more time to practice on using the model to have enough experience to work as a team with a role for each member.

In Fig. 22, The bars show that students receive quick responses for their requests as a post or a group message. Compared to the results that we observed in the case of social media only, the results for using LPSEAG model are fairly different. Moreover, students rank the availability of interactive features as high; because, we provide students with an application that facilitates the team members collaboration. Furthermore, students found that communicating with other team members easy as is shown in Fig. 23. These results are on the contract of the results we obtained when using social media only.

The rating of the efficiency of using LPSEAG model by students' responses in terms of supporting the different programming activities to solve assignments is significantly different than social media only (Fig. 24). Figure 24 shows that $50 \%$ of students' responses are strongly agree and agree with using LPSEAG to support working on different programming activities and $14 \%$ of students in average demonstrate a somewhat high. Furthermore, Fig. 25 shows that students rate the difficulty of solving assignments and working over distance with a group as low and very low. In Fig. 26, bars show that students didn't spent much time looking for help, responses show that $49 \%$ of the students rank the time that they spent waiting for help as low and very low and $21 \%$ of students rank it as somewhat high.

Figure 27 shows that the students solve the assignments with a high and very high speed with a rate of 30 and $24 \%$ respectively. The rate of students satisfactions about the communication reliability is $53 \%$ in total (high and very high). Furthermore, they rank the probability of errors to occur as low. Finally, the provided fidelity and awareness are ranked as high and very high by students (Fig. 28).

\section{Quantitative results}

In this part, we analyze and discuss the observed data from CAPS application and social media groups which reflects the student's interaction and behavior while they work on solving assignments. The spent time to complete the assignments, number of transferred messages between members and the number of errors that each team made. Furthermore, we analyze students' grades for each assignment. 


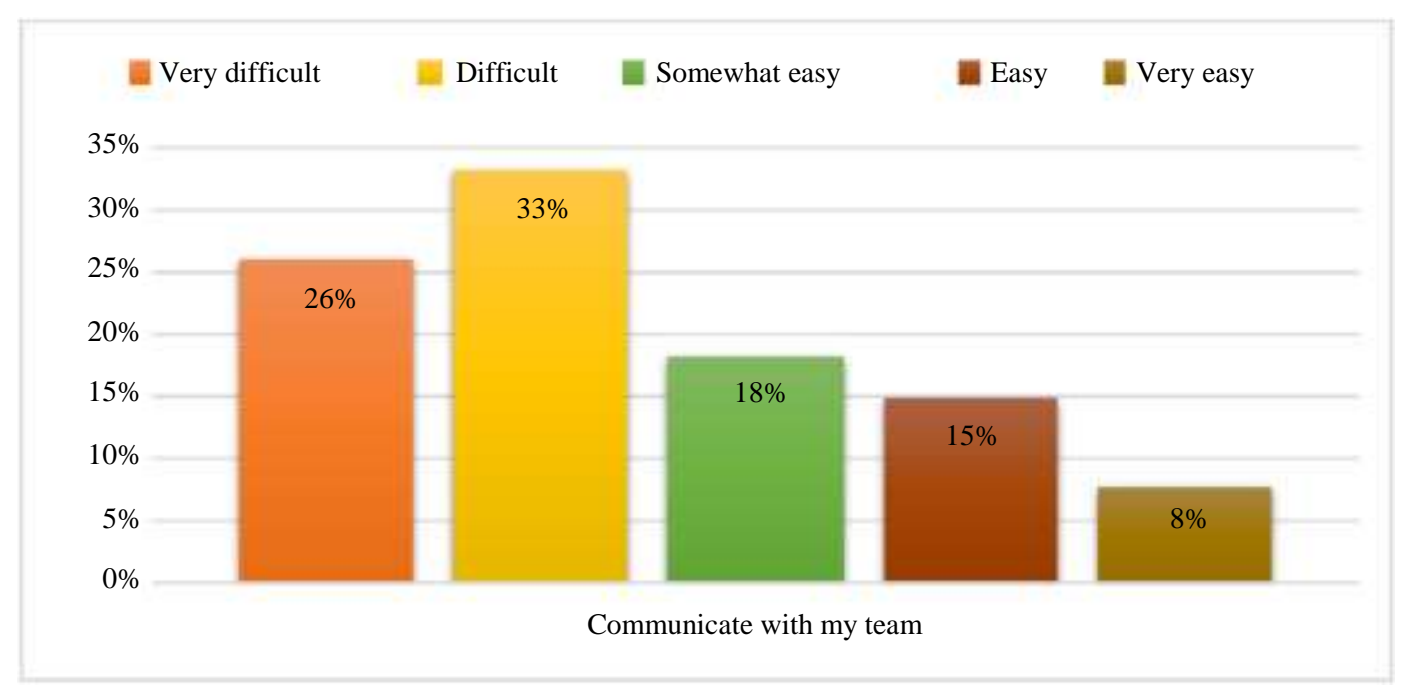

Fig. 15: Responses to the satisfaction of the difficulty to communicate with team members

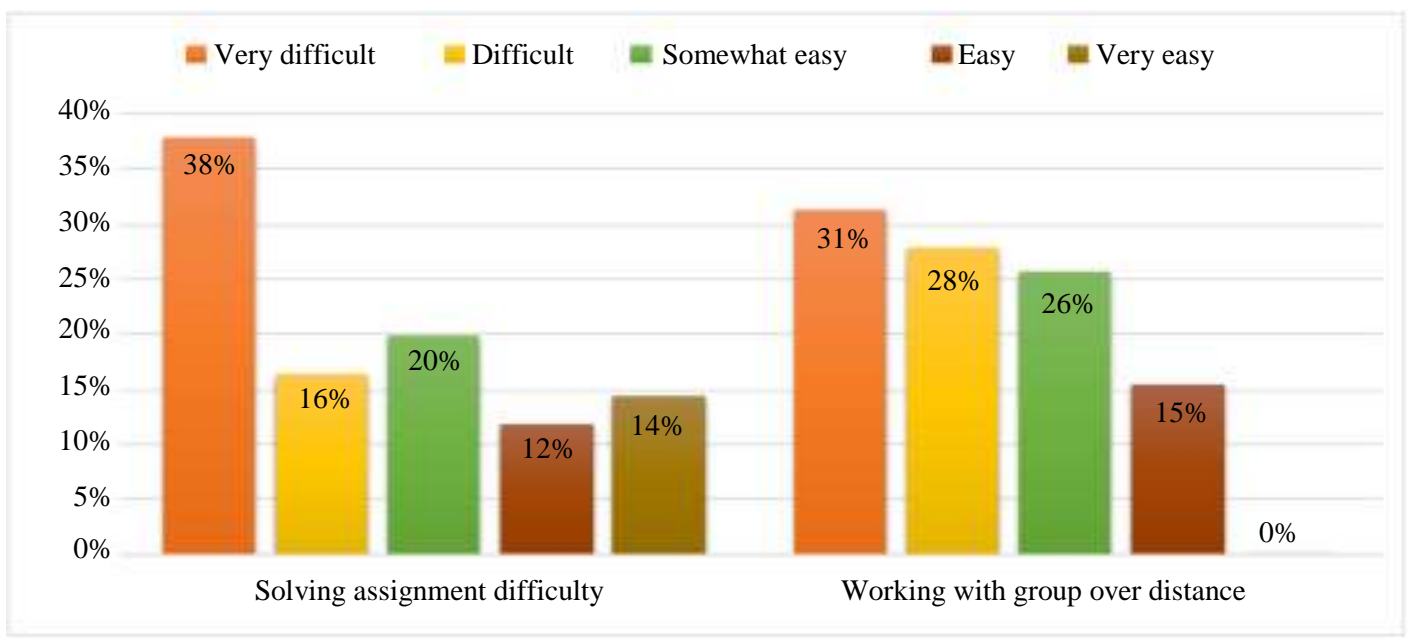

Fig. 16: The difficulty of solving assignment and working over-distance with a group

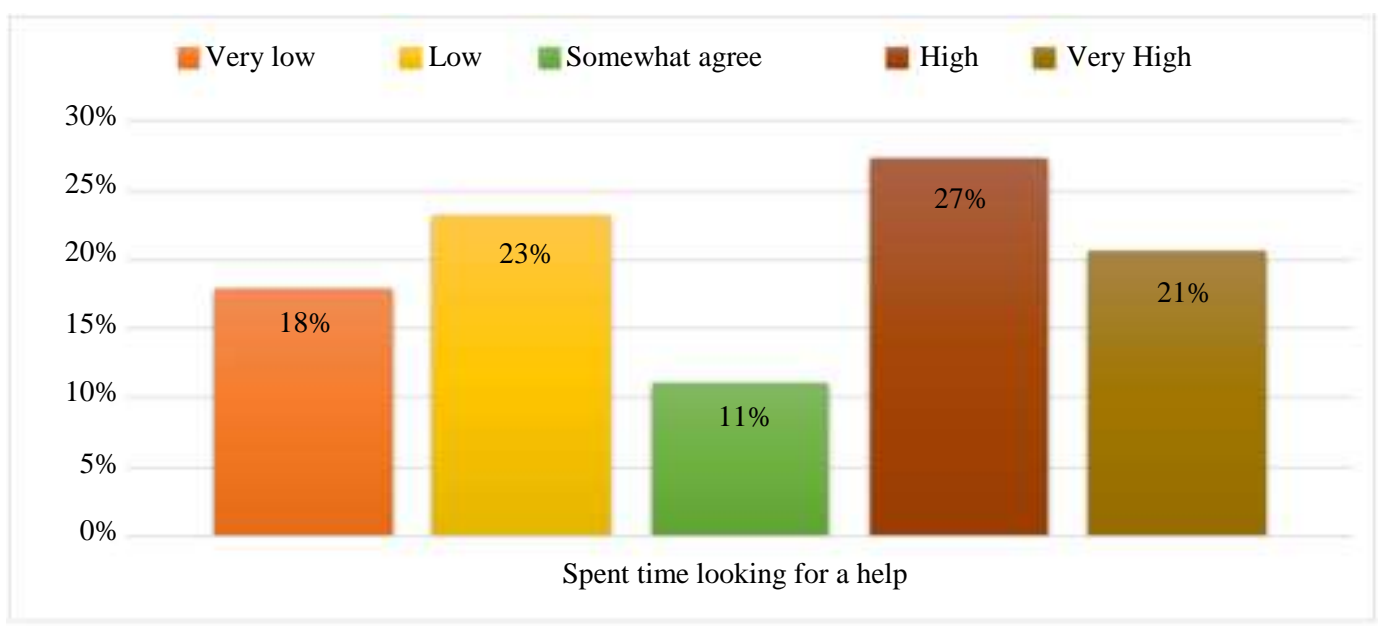

Fig. 17: The spent time looking for a help from other team members 




Fig. 18: Students' satisfaction as they work on different software developments life cycles: Analysis, design, coding, integrating and testing



Fig. 19: Responses to the satisfaction of solve problem speed, communication reliability and error possibility

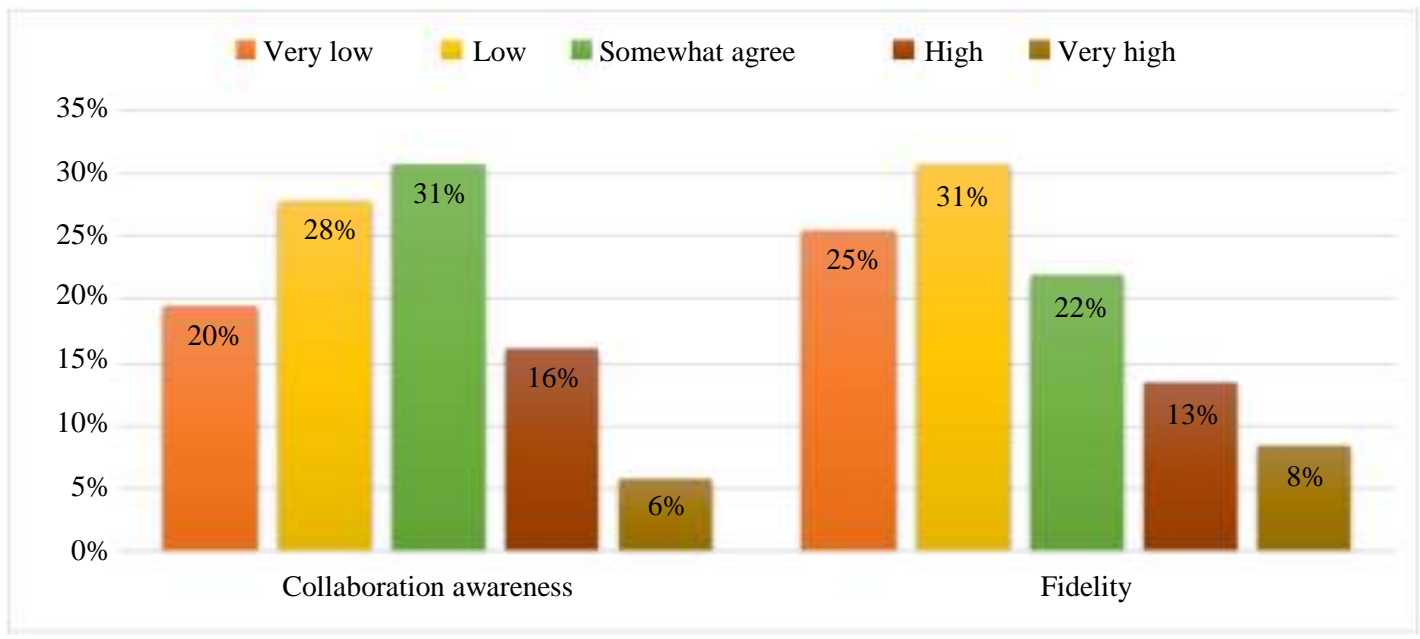

Fig. 20: The collaboration fidelity and awareness responses 


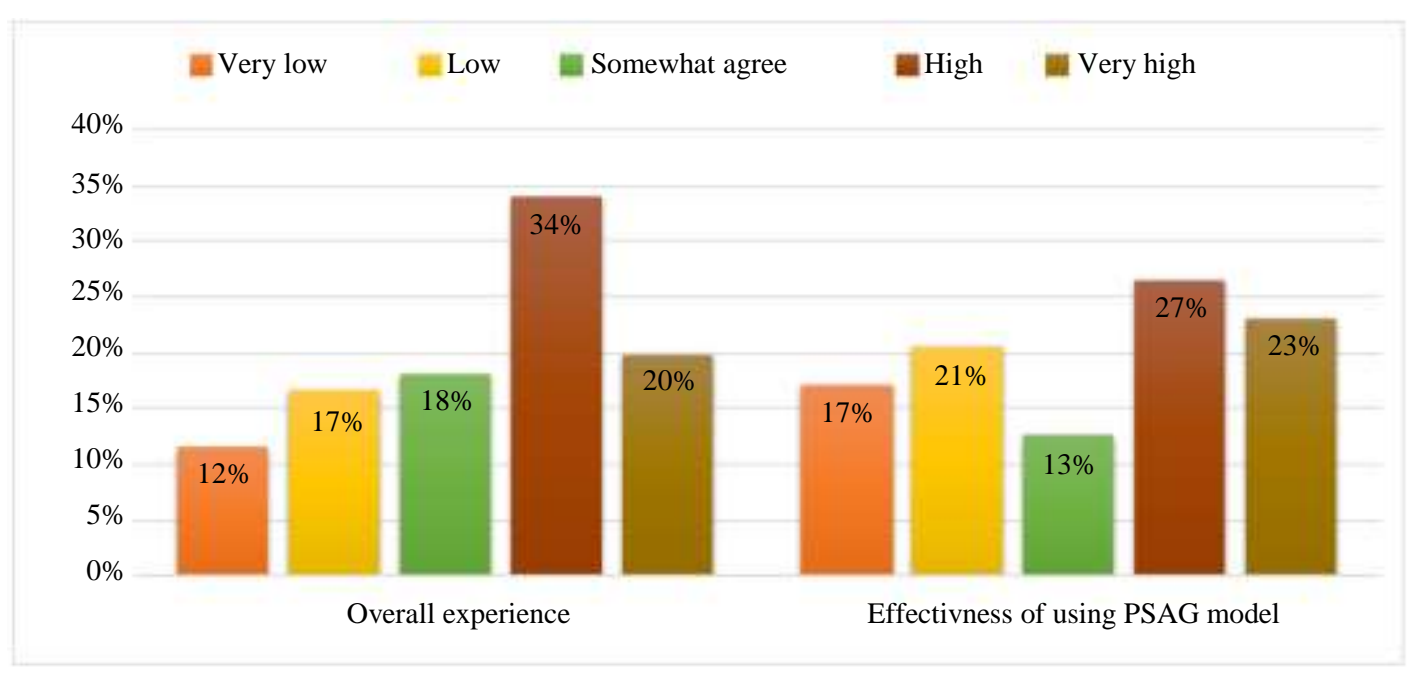

Fig. 21: The overall experience for all students using LPSEAG

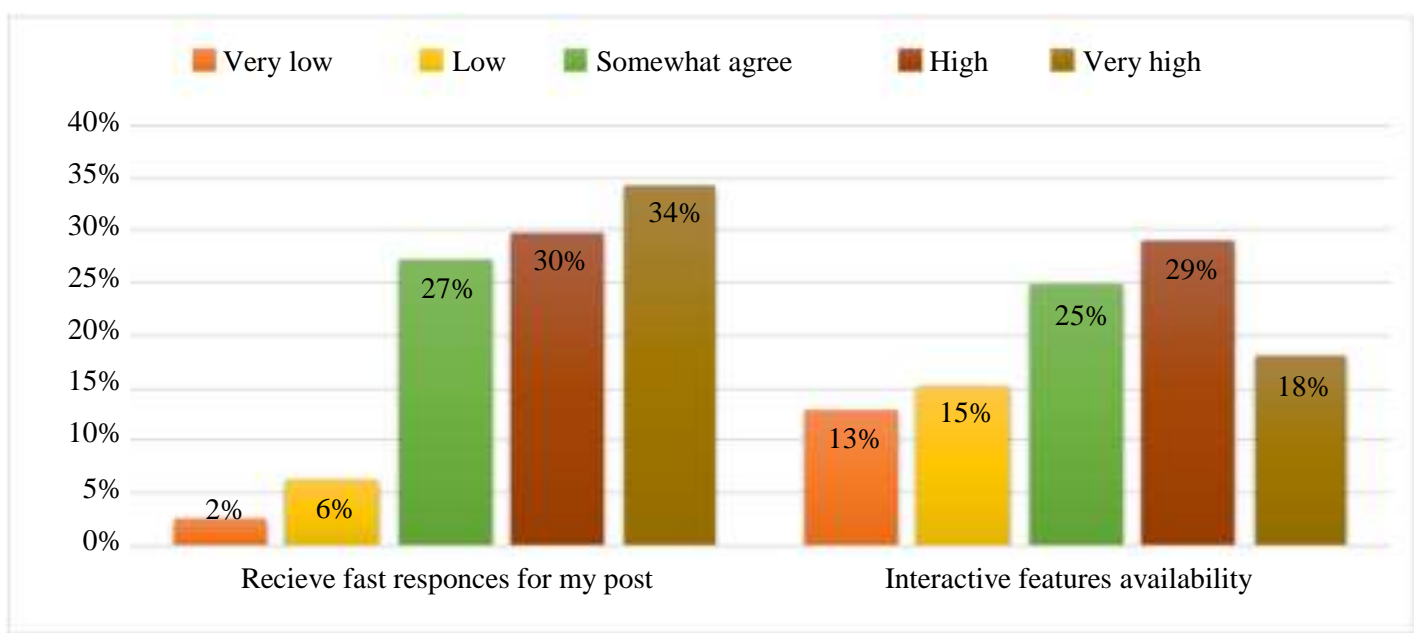

Fig. 22: Students responses for receiving help from teammate and the availability of interactive features

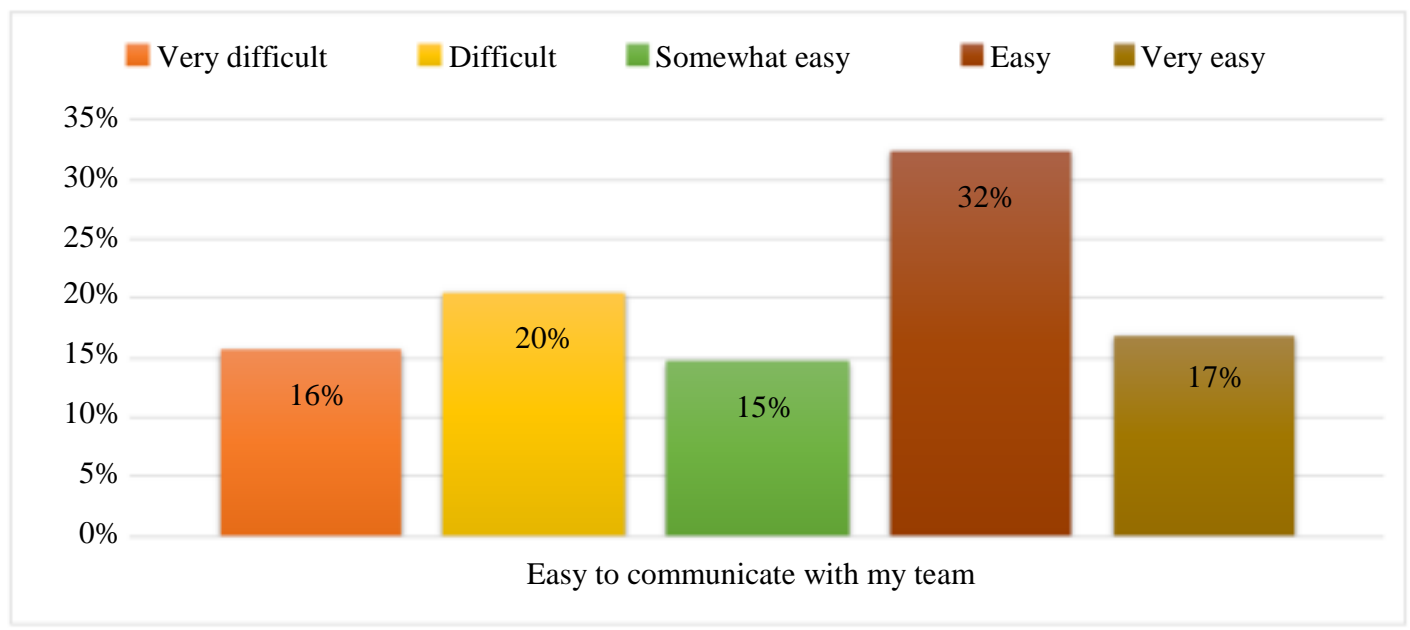

Fig. 23: Students' satisfaction of the difficulty to communicate with team members 


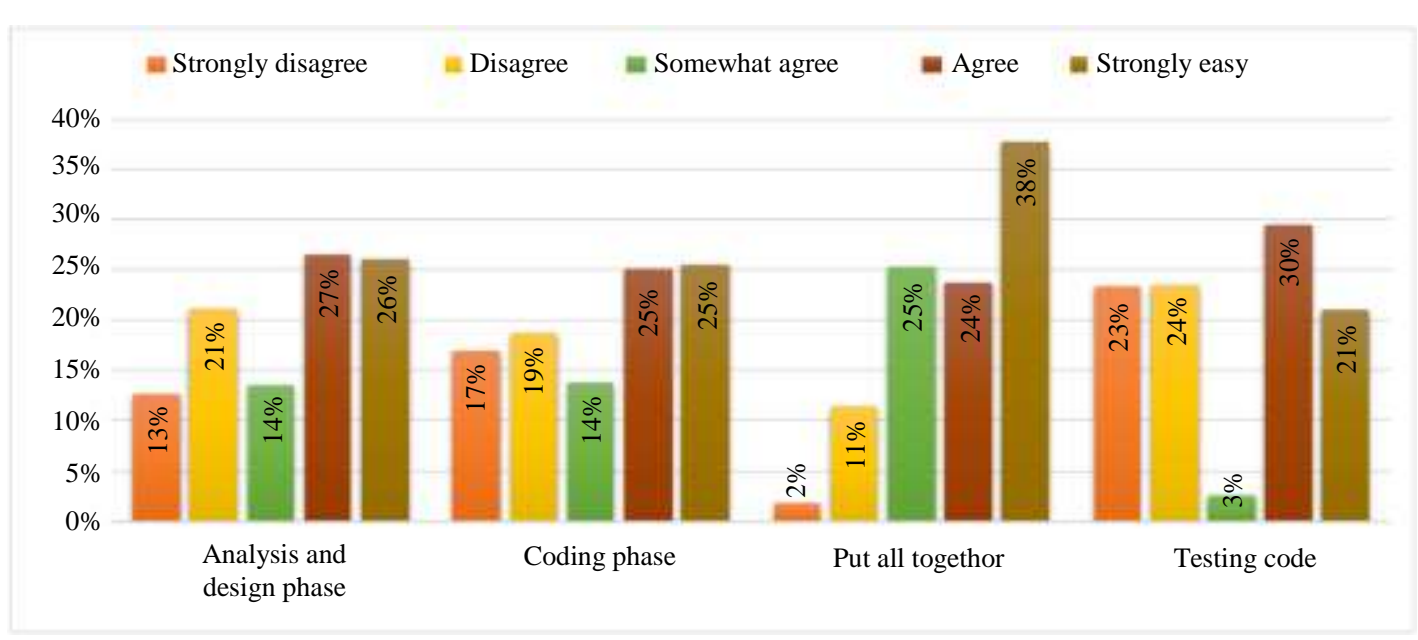

Fig. 24: Students' satisfaction as they work on different software developments life cycles: Analysis, design, implementation, integration and testing

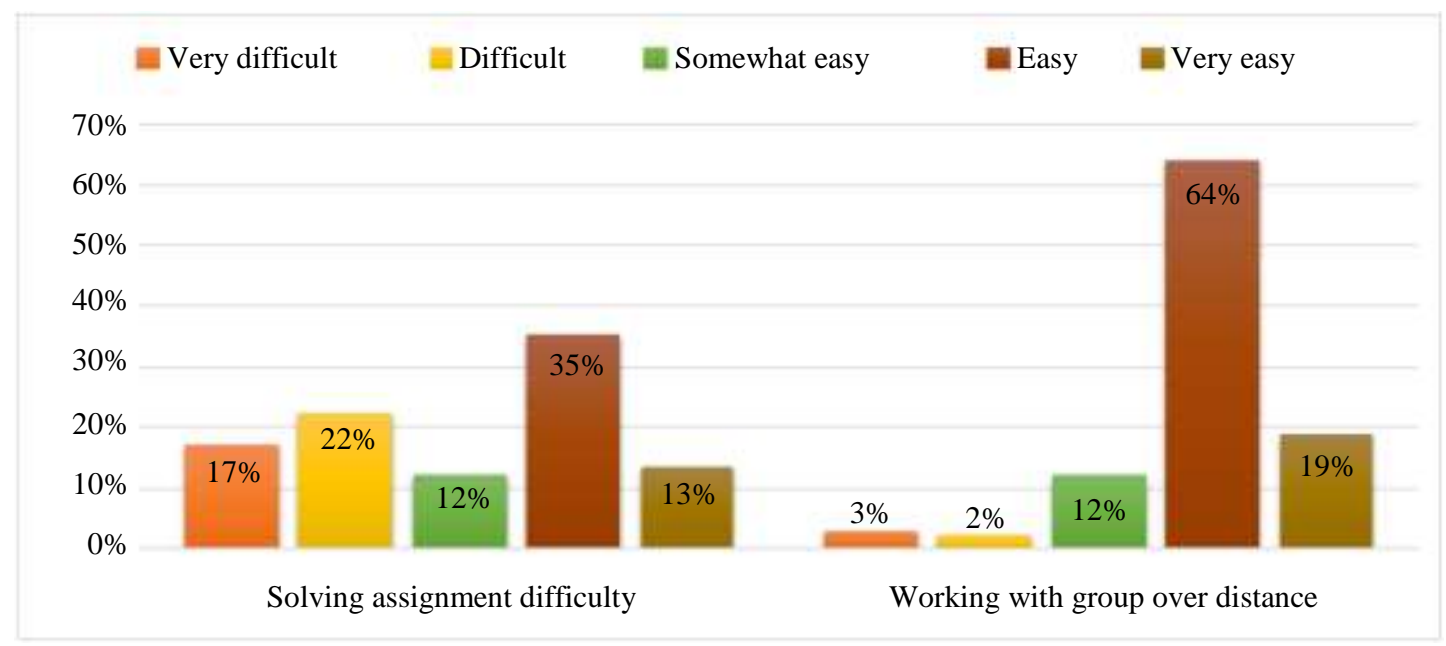

Fig. 25: The difficulty of solving assignment and working with a group over distance

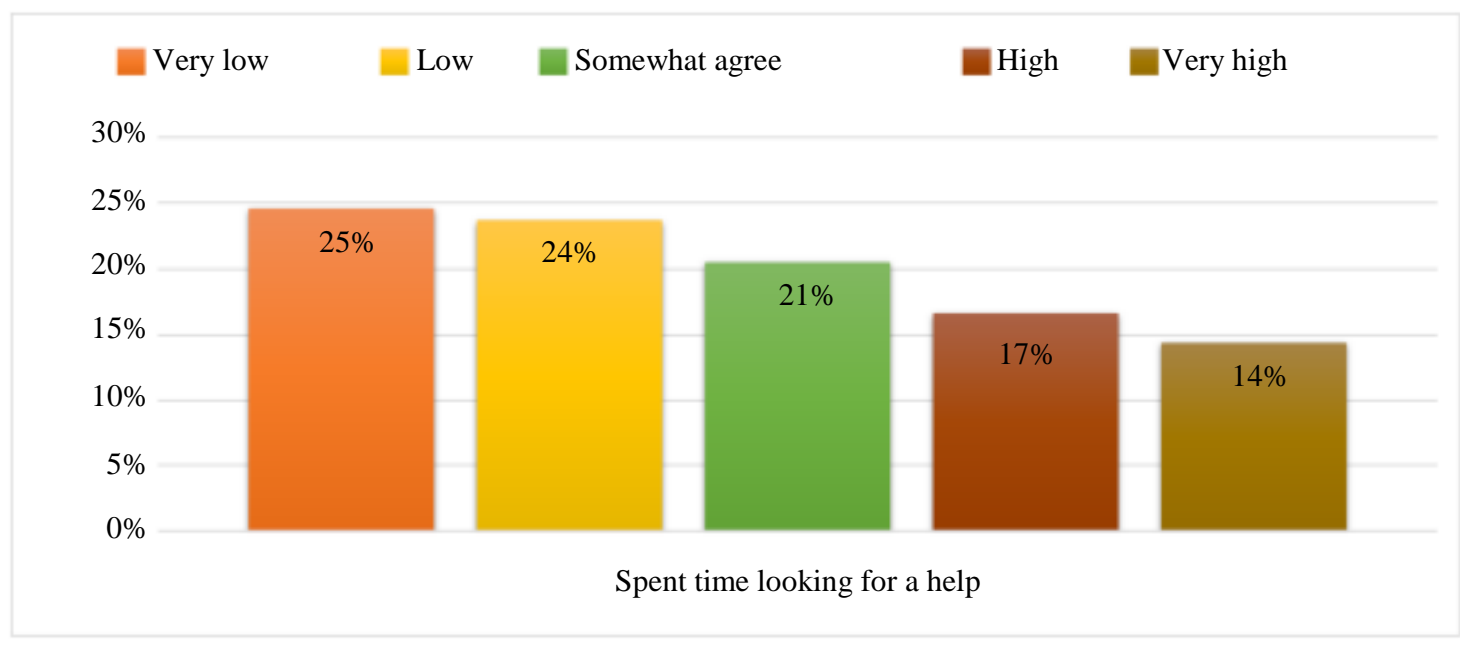

Fig. 26: The spent time looking for a help from other team members 


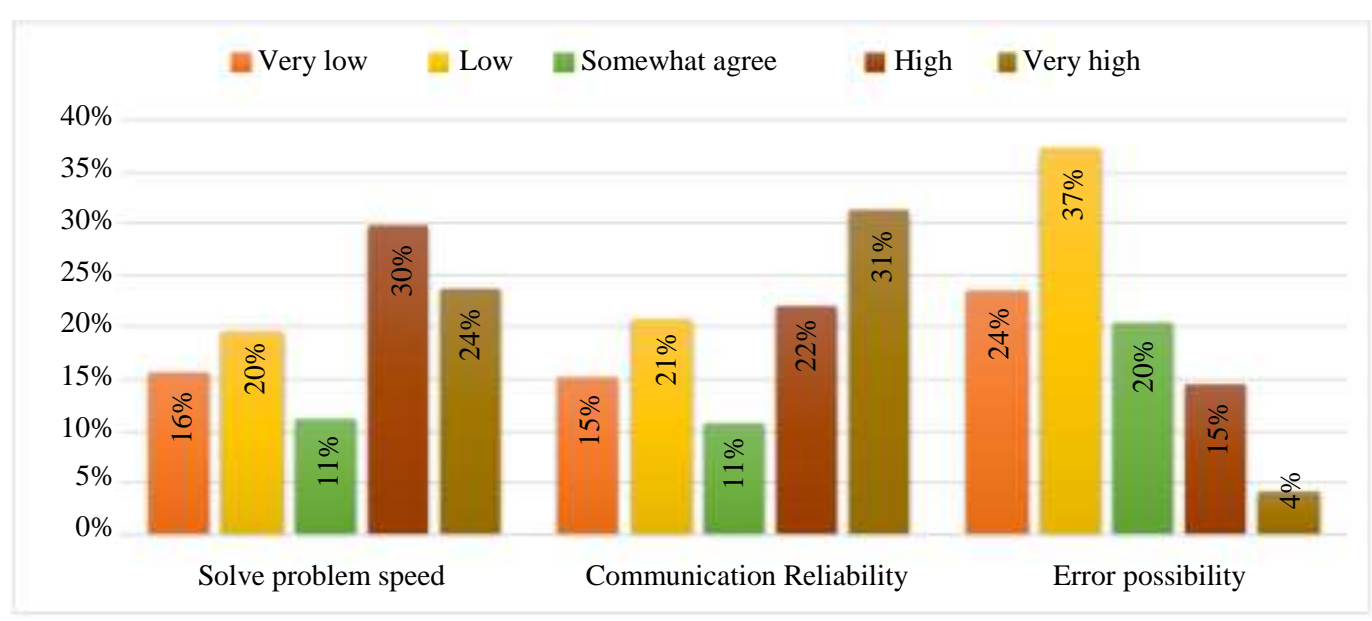

Fig. 27: Responses to the satisfaction of solve problem speed, communication reliability and error possibility Spent time looking for a help

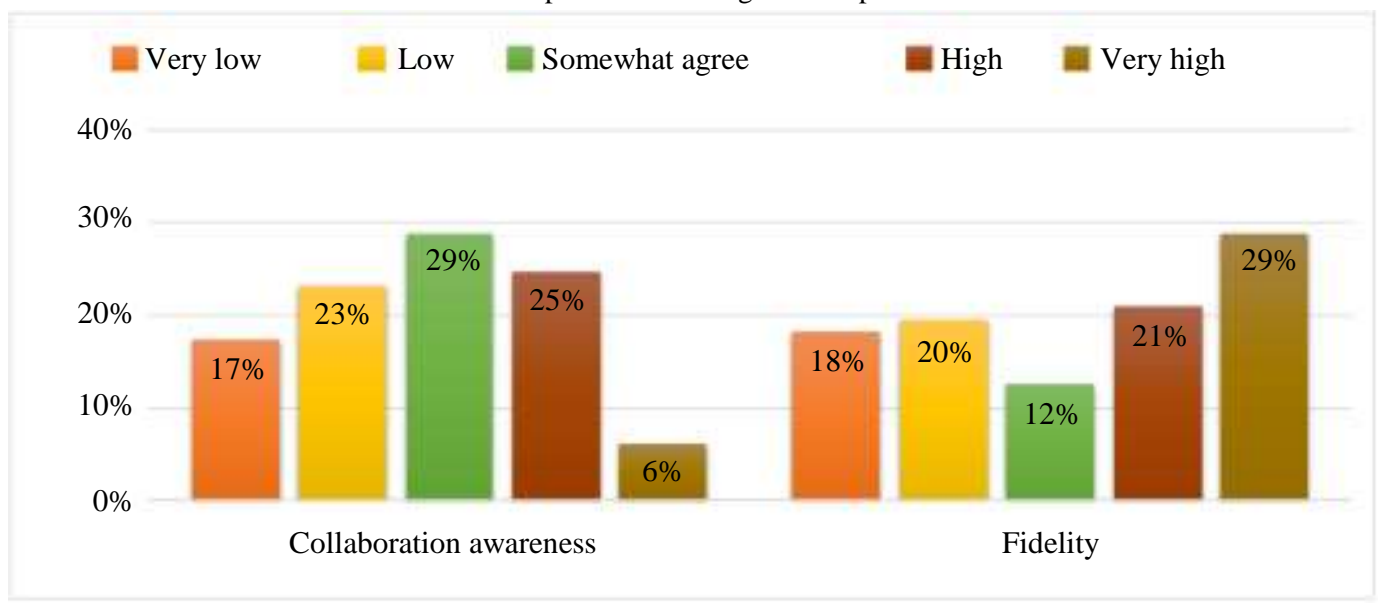

Fig. 28: Students responses to the two collaboration components: the awareness on left and the fidelity on right

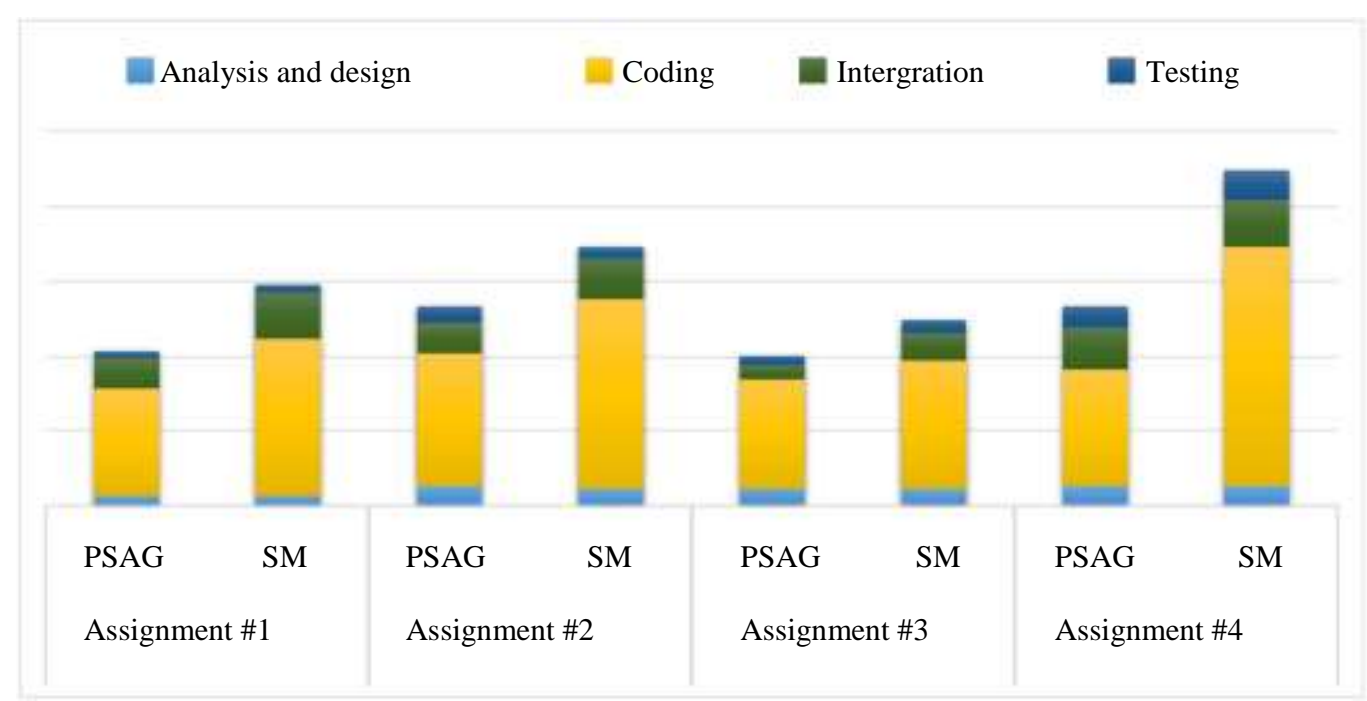

Fig. 29: The average of spent time to solve each assignment using LPSEAG model and Social media only 


\section{Timeline Experiment Analysis}

CAPS application allows members to record the spent time in each phase as they work on the assignments. This feature is available for all teams, therefore we compare the spent time in each assignment for teams that use LPSEAG model and teams that use social media only. The results show that the total time spent to solve each assignment by teams that use LPSEAG model is significantly less than the total time spent by the other teams. Furthermore, the analysis and design time is somehow similar, but the main difference is founded in the time required for coding and integration. Figure 29 shows the average time spent solving the four assignments. Monitoring the work of each team, we found that teams that use social media only spend more time transferring messages with repeated ideas, questions, etc. where teams that use LPSEAG model are more organized and divide the work between members more specifically.

\section{Analysis of Number of Errors and the Transferred Messages Between Members}

We asked students to record the number of errors that they have after each phase; syntax and logic errors. At the same time the instructor records the number of errors that each team made while s/he is grading the assignment (AlJarrah and Pontelli, 2016; 2020). We compute the average number of errors in each assignment in all courses. Figure 30 shows that the number of errors made by LPSEAG teams is less than the number of errors made by SM teams.
A t-test analysis applied to the number of errors in both categories of teams which outputs the value of $\mathrm{P}=$ 0.005569 , where we test $\mathrm{P}$ to be less than 0.05 . Hence, the score for LPSEAG model is significantly different, where $\mathrm{M}=9.3$ and $\mathrm{SD}=2.68$ for LPSEAG and $\mathrm{M}=15.6$ and $\mathrm{SD}=4.0816$ for $\mathrm{SM}$ and $\mathrm{P}=0.005569$.

Each member creates a group on social media where they use it to make discussions, share information, send files, etc. The analysis of transferred messages over social media for both categories of teams shows that the transferred messages by LPSEAG teams where more specific and direct to the discussion topic, it is because each member in the team knows what his/her role is in the group exactly and what his/her contribution should be for the success of the group. Therefore, the transferred questions or feedback are clear and not repeated. Comparatively, LPSEAG model defines the time line clearly for each member, therefore, the required activity over social media is specific and less than the amount of activity by SM teams, which results in more time spent on messaging by SM teams.

\section{Students' Grades}

The assignments were designed in the context of pedagogical for each course. Each assignment is graded out of ten. Therefore, we compare the students' results in each course, where we found a significant difference between students' grades who are members of LPSEAG teams and students' grades who are members in SM teams. The bar charts in Fig. 31 shows the differences between students grades in all courses, where the bars in the chart are the medium of each assignment's grades out of 10 .

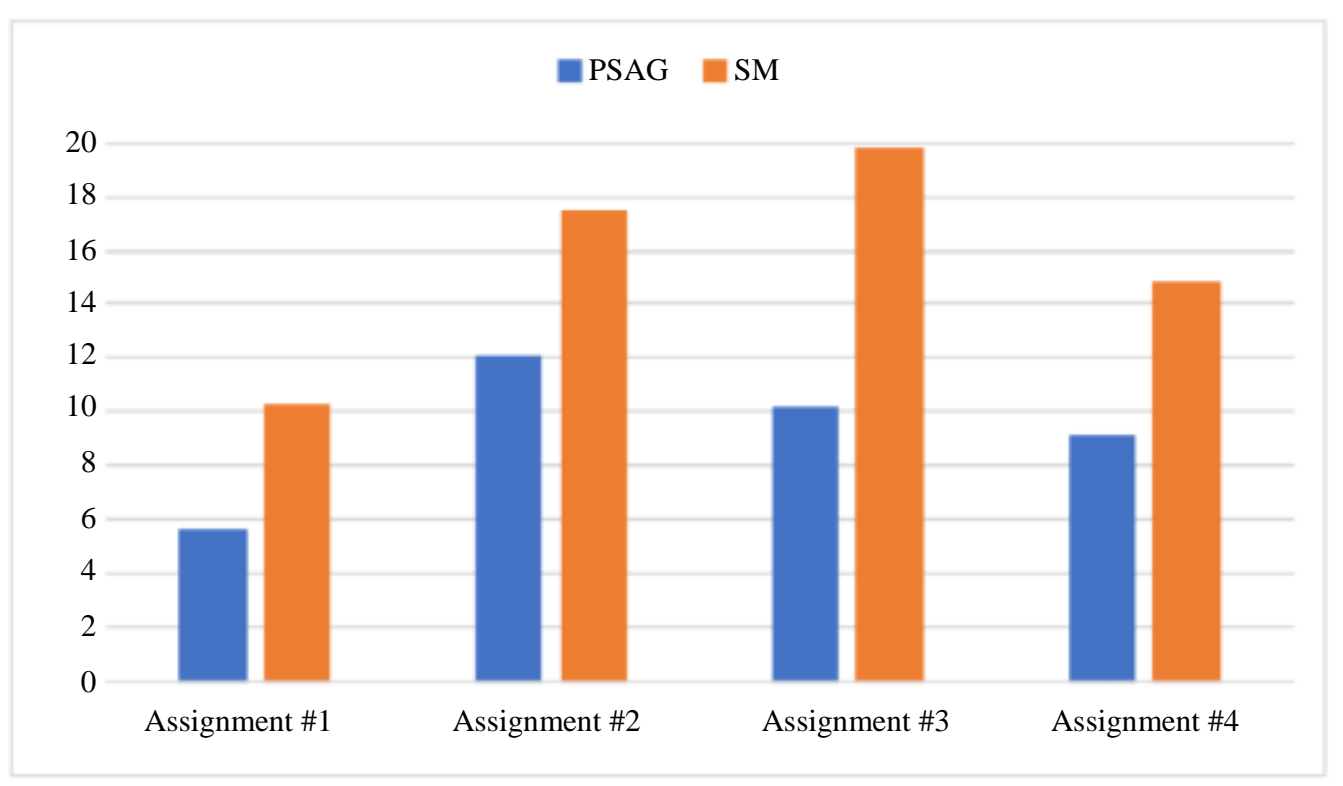

Fig. 30: The average number of errors that each team have in each assignment using LPSEAG and SM 
- $\mathrm{LPSEAG}$ - $\mathrm{SM}$

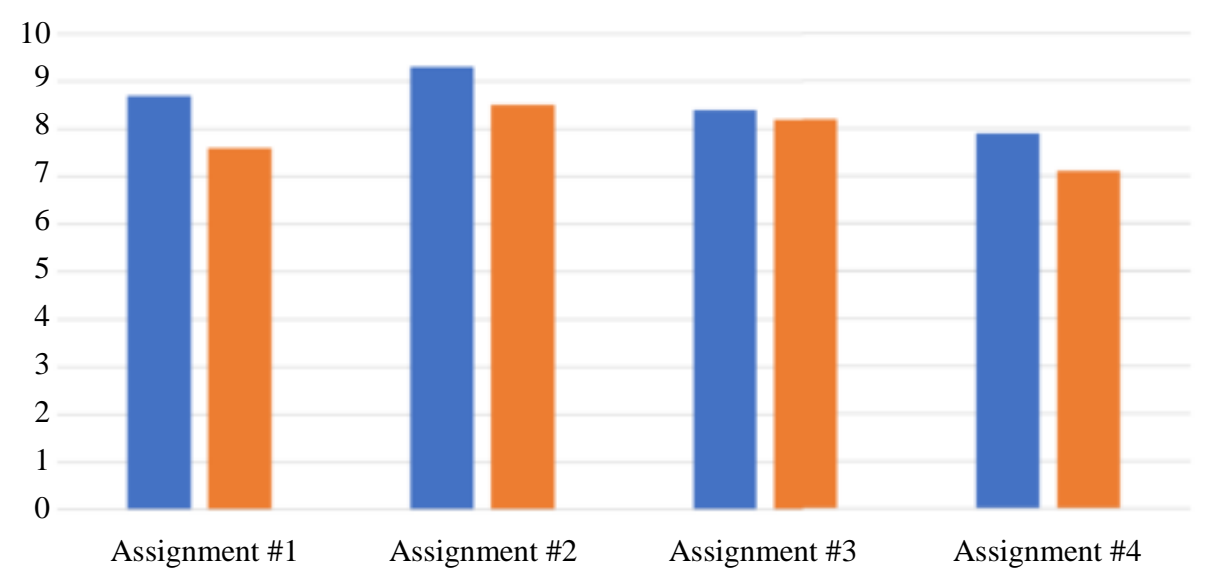

(a)

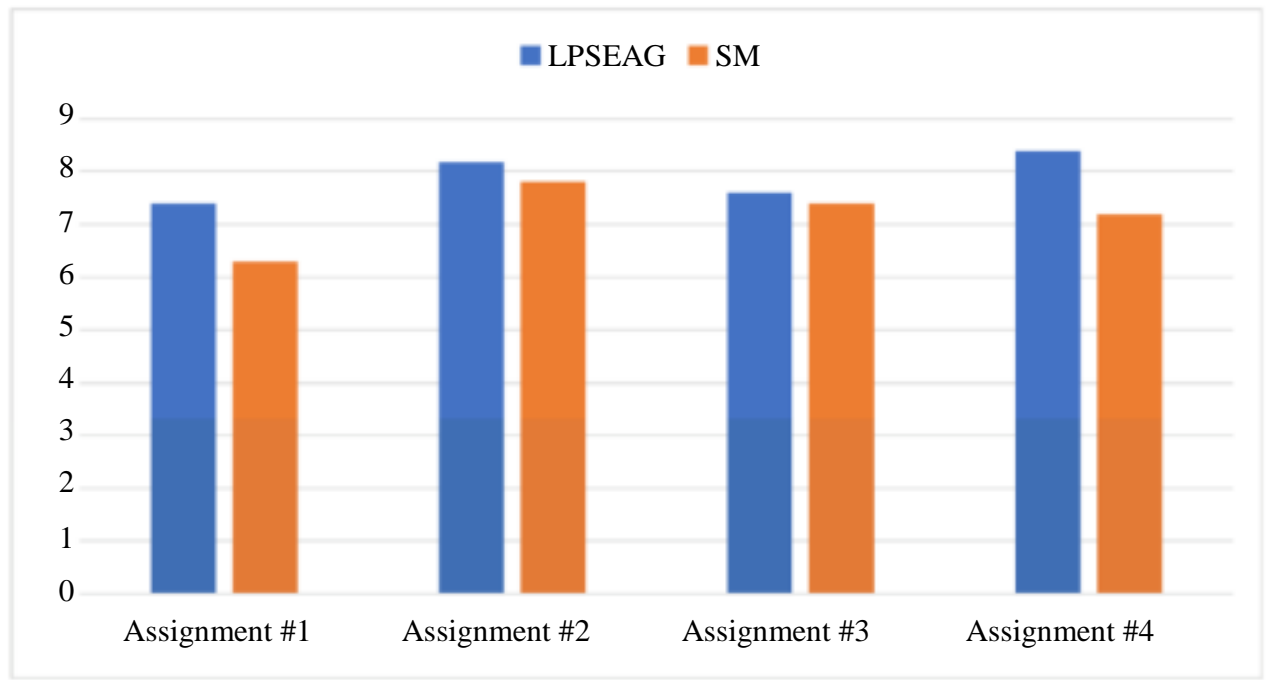

(b)

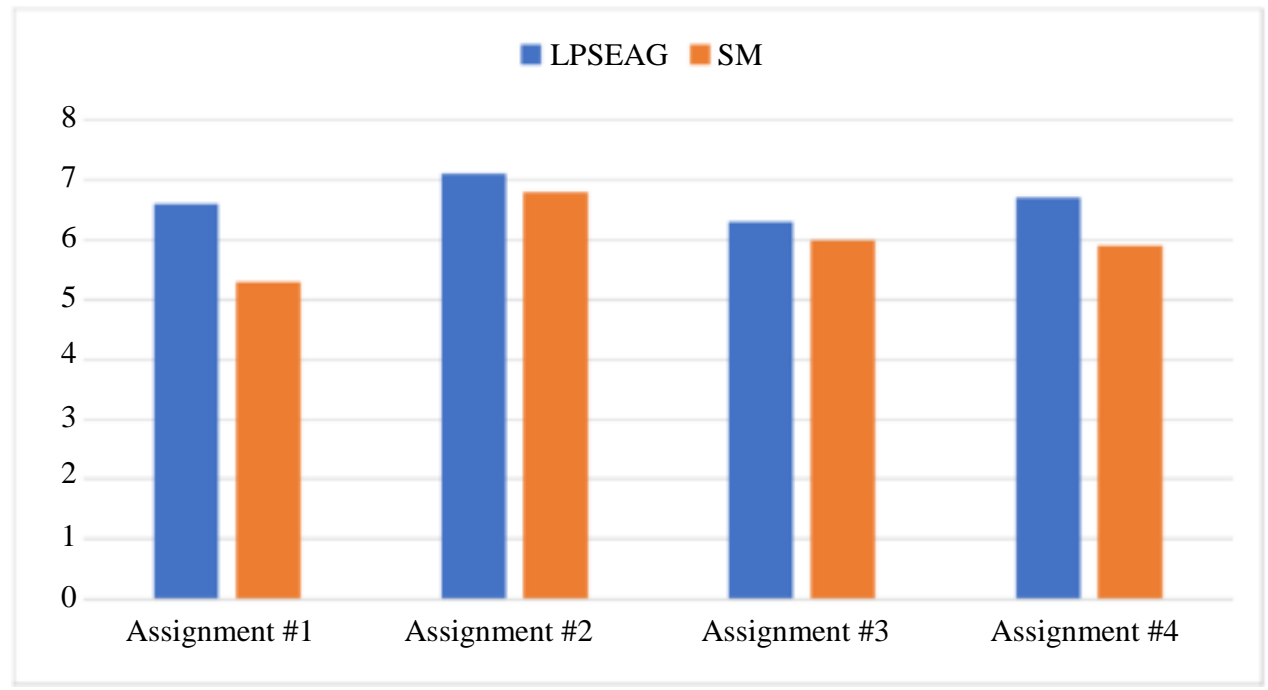

(c) 


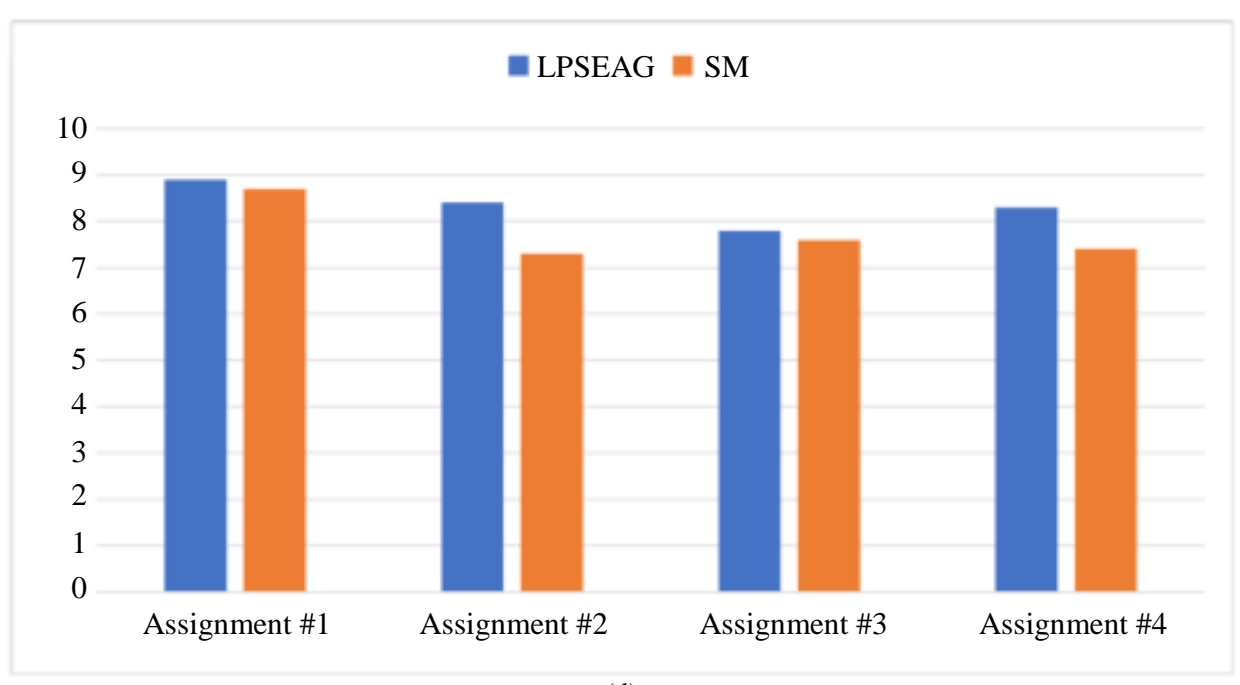

(d)

Fig. 31: The students grades in C++, Java, OOP and Python courses (all grades for assignments only out of 10); (a) C++ grades; (b) Java grades; (c) OPP grades; (d) Python grades

A t-test analysis applied to the students' grades in the four courses for all students in both teams' categories (LPSEAG teams and SM teams). A t-test analysis for C++ course outputs the value of $\mathrm{P}=0.01556$, where $\mathrm{P}$ is tested to be less than 0.05 . Hence, the score for LPSEAG model is significantly different, where $\mathrm{M}=8.575$ and $\mathrm{SD}=0.585$ for LPSEAG model and $\mathrm{M}=7.85$ and $\mathrm{SD}=0.624$ for $\mathrm{SM}$ and $\mathrm{P}=0.01556$.

A t-test analysis for Java course outputs the value of $\mathrm{P}=$ 0.0311 , where $\mathrm{P}$ is tested to be less than 0.05 . Hence, the score for LPSEAG model is significantly different, where M $=7.9$ and $\mathrm{SD}=0.476$ for LPSEAG model and $\mathrm{M}=7.175$ and $\mathrm{SD}=0.6344$ for $\mathrm{SM}$ and $\mathrm{P}=0.0311$. Moreover, the $\mathrm{t}-$ test analysis for OOP course outputs the value of $\mathrm{P}=$ 0.03336 , where $P$ is tested to be less than 0.05 . Hence, the score for LPSEAG model is significantly different, where $\mathrm{M}$ $=6.675$ and $\mathrm{SD}=0.3304$ for LPSEAG model and $\mathrm{M}=6$ and $\mathrm{SD}=0.6164$ for $\mathrm{SM}$ and $\mathrm{P}=0.03336$.

The appearance of significant difference was confirmed once again by the t-test on the grades of Python course for LPSEAG team members Vs. SM team members. The test outputs $\mathrm{P}=0.04166$, where $\mathrm{P}$ is tested to be less than 0.05 . Hence, the score for LPSEAG model is significantly different, where $\mathrm{M}=8.35$ and $\mathrm{SD}=0: 4509$ for LPSEAG model and $\mathrm{M}=7.75$ and $\mathrm{SD}=0.6454$ for SM and $\mathrm{P}=0.04166$.

\section{Fisher's Exact Test}

In this experiment, we study the effects of integrating ARG with using social media in learning programming as a CVE. In this part, we perform a statistical analysis using Fisher's exact test (McDonald, 2009) that it can be summarized as:

$$
\frac{((a+b) !(c+d) !(a+c) !(b+d) !)}{a ! * b ! * c ! * d ! * N}
$$

We collected the responses for fifteen statements from students that we took from post-surveys. The students' answers from using the two approaches for using social media as a collaborative learning environment are compared. The followings are the two hypotheses (null and alternative) that are suggested to test the proposed model:

- $H_{0}$ : There is no effect of using social media in learning over distance on learning outcomes in the context of ARG model

- $H_{1}$ : There is an effect of using social media in learning over distance on learning outcomes in the context of ARG model

The main reason of using Fisher test, because it is an effective statistical significant test with a small sample size. The following is a quick summarize of the analysis of the key questions:

- Statement 1: The overall experience is good to work with a team over-distance using social media with ARG model (Table 4).

- $\mathrm{P}$-value $=2.367 e-14$

- Alternative hypothesis: true odds ratio is not equal to 1

- The range of confidence interval of $95 \%$ are lies between 0.3003672 and 0.4986141

- Odds ratio $=0.3874278$

- We rejected the null hypothesis, because p < $a(286)$. There is evidence that the extension of using ARG model with social media for overdistance learning purpose increases the participants' involvement 
- $\quad$ Statement 2: There is a high effectiveness of using social media with the extension of ARG in the purpose of over-distance learning (Table 5):

- $\quad \mathrm{P}-$ value $=4.017 e-10$

- Alternative hypothesis: True odds ratio is not equal to 1

- The range of confidence interval of $95 \%$ are lies between 0.3675699 and 0.5989318

- $\quad$ Odds ratio $=0.469544$

- We rejected the null hypothesis, because p < $a(321)$

- Statement 3: It was easy to communicate and collaborate over-distance with a team (Table 6):

- $\quad$-value $=9: 138 e-15$

- Alternative hypothesis: True odds ratio is not equal to 1

- The range of confidence interval of $95 \%$ are lies between 0.3052384 and 0.4996550

- $\quad$ Odds ratio $=0.390878$

- We rejected the null hypothesis, because p < $a(336)$

- Statement 4: It was easy to work with a team to analyze the assignment and design the solution (Table 7):

- $\mathrm{P}$-value $<2.2 e-16$

- Alternative hypothesis: True odds ratio is not equal to 1

- The range of confidence interval of $95 \%$ are lies between 0.1917588 and 0.3189689

- $\quad$ Odds ratio $=0.2476576$

- We rejected the null hypothesis, because p < $a(383)$

- Statement 5: Implementing the solution was easy while working over-distance with team (Table 8):

- $\quad$-value $=6.414 e-07$

- Alternative hypothesis: True odds ratio is not equal to 1

- $\quad$ The range of confidence interval of $95 \%$ are lies between 0.4266539 and 0.6959771

- $\quad$ Odds ratio $=0.5452696$

- We rejected the null hypothesis, because p < $a(287)$

- $\quad$ Statement 6: It was easy to integrate the code parts that were created separately by each group member (Table 9):

- $\quad \mathrm{P}$-value $<2.2 e-16$

- Alternative hypothesis: True odds ratio is not equal to 1

- $\quad$ The range of confidence interval of $95 \%$ are lies between 0.07402825 and 0.13658973
- $\quad$ Odds ratio $=0.1009786$

- We rejected the null hypothesis, because p < $a(342)$

- $\quad$ Statement 7: It was easy to on testing phase (Table 10):

- $\quad$-value $=0.514$

- Alternative hypothesis: True odds ratio is not equal to 1

- The range of confidence interval of $95 \%$ are lies between 0.7232184 and 1.1676526

- $\quad$ Odds ratio $=0.9190321$

- We rejected the null hypothesis, because p < $a(279)$

- $\quad$ Statement 8: It was easy to work over-distance with a team to solve the assignment problem (Table 11):

- $\quad$-value $=7.817 e-07$

- Alternative hypothesis: True odds ratio is not equal to 1

- $\quad$ The range of confidence interval of $95 \%$ are lies between 0.4316795 and 0.7011648

- $\quad$ Odds ratio $=0.5504836$

- We rejected the null hypothesis, because p < $a(308)$

- $\quad$ Statement 9: Working over distance with a group was easy (Table 12):

- $\mathrm{P}$-value $<2.2 e-16$

- Alternative hypothesis: True odds ratio is not equal to 1

- The range of confidence interval of $95 \%$ are lies between 0.02389886 and 0.05659260

- $\quad$ Odds ratio $=0.03737841$

- We rejected the null hypothesis, because p < $a(336)$

- Statement 10: It was fast to receive help from group members according to the collaboration time (Table 13):

- $\quad$ - value $=0.01705$

- Alternative hypothesis: True odds ratio is not equal to 1

- The range of confidence interval of $95 \%$ are lies between 1.052042 and 1.704593

- $\quad$ Odds ratio $=1.33874$

- We rejected the null hypothesis, because p < $a(234)$

- Statement 11: According to the collaboration time, it was fast to collaborate with a group to solve the assignment problem (Table 14):

- $\quad$ P-value $=1.503 e-09$

- Alternative hypothesis: True odds ratio is not equal to 1 
- The range of confidence interval of $95 \%$ are lies between 0.3752168 and 0.6127025

- $\quad$ Odds ratio $=0.4798129$

- We rejected the null hypothesis, because $\mathrm{p}<$ $a(303)$

- Statement 12: It was reliable to communicate with a group using available communication media (Table 15):

- $\mathrm{P}-$ value $=0.1493$

- Alternative hypothesis: True odds ratio is not equal to 1

- The range of confidence interval of $95 \%$ are lies between 0.9371917 and 1.5570377

- $\quad$ Odds ratio $=1.207648$

- We rejected the null hypothesis, because $\mathrm{p}<$ $a(180)$

- Statement 13: The possibility to have errors is a low while working over distance with a team (Table 16):

- $\mathrm{P}-$ value $=6.173 \mathrm{e}-10$

- Alternative hypothesis: True odds ratio is not equal to 1

- The range of confidence interval of $95 \%$ are lies between 1.655065 and 2.694497

- $\quad$ Odds ratio $=2.110267$

- We rejected the null hypothesis, because $\mathrm{p}<$ $a(241)$

- Statement 14: The system provides enough information about what the member teammates are doing (Table 17):

- $\mathrm{P}$-value $=0.02706$

- Alternative hypothesis: True odds ratio is not equal to 1

- The range of confidence interval of $95 \%$ are lies between 0.5985304 and 0.9705211

- $\quad$ Odds ratio $=0.7623837$

- We rejected the null hypothesis, because $\mathrm{p}<$ $a(269)$

- Statement 15: The system provide up-to-date and correct information which let it easy to work with the group (Table 18):

- $\quad$ P-value $=5.861 \mathrm{e}-10$

- Alternative hypothesis: True odds ratio is not equal to 1

- The range of confidence interval of $95 \%$ are lies between 0.3702246 and 0.6031720

- Odds ratio $=0.4729072$

- We rejected the null hypothesis, because $\mathrm{p}<$ $a(320)$
Table 4: Table statement 1

\begin{tabular}{|c|c|c|c|c|}
\hline & \multicolumn{4}{|c|}{ Observed Data } \\
\hline & SM & LPSEAG & Total & Expected \\
\hline Low & $a=286$ & $\mathrm{~b}=160$ & 446 & 223 \\
\hline High & $c=283$ & $\mathrm{~d}=409$ & 692 & 346 \\
\hline Total & 569 & 569 & 1138 & 569 \\
\hline
\end{tabular}

Table 5: Table Statement 2

\begin{tabular}{lllrl}
\hline & Observed data & & \\
& SM & LPSEAG & Total & Expected \\
\hline Low & $\mathrm{a}=321$ & $\mathrm{~b}=215$ & 536 & 268 \\
High & $\mathrm{c}=248$ & $\mathrm{~d}=354$ & 602 & 301 \\
Total & 569 & 569 & 1138 & 569 \\
\hline
\end{tabular}

Table 6: Table Statement 3

\begin{tabular}{|c|c|c|c|c|}
\hline & \multicolumn{4}{|c|}{ Observed data } \\
\hline & SM & LPSEAG & Total & Expected \\
\hline Low & $a=336$ & $b=205$ & 541 & 270.50 \\
\hline High & $c=233$ & $d=364$ & 597 & 298.50 \\
\hline Total & 569 & 569 & 1138 & 569.00 \\
\hline
\end{tabular}

Table 7: Table Statement 4

\begin{tabular}{|c|c|c|c|c|}
\hline & \multicolumn{4}{|c|}{ Observed data } \\
\hline & $\mathrm{SM}$ & LPSEAG & Total & Expected \\
\hline Disagree & $a=383$ & $b=192$ & 575 & 287.50 \\
\hline Agree & $c=186$ & $d=377$ & 563 & 281.50 \\
\hline Total & 569 & 569 & 1138 & 569.00 \\
\hline
\end{tabular}

Table 8: Table Statement 5

\begin{tabular}{lllrl}
\hline & \multicolumn{2}{l}{ Observed Data } & & \\
& --------------------------- \\
& SM & LPSEAG & Total & Expected \\
\hline Disagree & $\mathrm{a}=287$ & $\mathrm{~b}=203$ & 490 & 245 \\
Agree & $\mathrm{c}=282$ & $\mathrm{~d}=366$ & 648 & 324 \\
Total & 569 & 569 & 1138 & 569 \\
\hline
\end{tabular}

Table 9: Table Statement 6

\begin{tabular}{lllrl}
\hline & \multicolumn{2}{l}{ Observed data } & & \\
& --------------------------------- \\
& SM & LPSEAG & Total & Expected \\
\hline Disagree & $\mathrm{a}=342$ & $\mathrm{~b}=75$ & 417 & 208.50 \\
Agree & $\mathrm{c}=227$ & $\mathrm{~d}=494$ & 721 & 360.50 \\
Total & 569 & 569 & 1138 & 569.00 \\
\hline
\end{tabular}

Table 10: Table Statement 7

\begin{tabular}{lllrl}
\hline & \multicolumn{2}{l}{ Observed data } & & \\
& SM & LPSEAG & Total & Expected \\
\hline Disagree & $\mathrm{a}=279$ & $\mathrm{~b}=267$ & 546 & 273 \\
Agree & $\mathrm{c}=290$ & $\mathrm{~d}=302$ & 592 & 296 \\
Total & 569 & 569 & 1138 & 569 \\
\hline
\end{tabular}


Table 11: Table Statement 8

\begin{tabular}{|c|c|c|c|c|}
\hline & \multicolumn{4}{|c|}{ Observed data } \\
\hline & SM & LPSEAG & Total & Expected \\
\hline Difficult & $a=308$ & $b=224$ & 532 & 266 \\
\hline Easy & $c=261$ & $d=345$ & 606 & 303 \\
\hline Total & 569 & 569 & 1138 & 569 \\
\hline
\end{tabular}

Table 12: Table Statement 9

Observed data

\begin{tabular}{lllrl} 
& SM & LPSEAG & Total & Expected \\
\hline Difficult & $\mathrm{a}=336$ & $\mathrm{~b}=29$ & 365 & 182.50 \\
Easy & $\mathrm{c}=233$ & $\mathrm{~d}=540$ & 773 & 286.50 \\
Total & 569 & 569 & 1138 & 569.00 \\
\hline
\end{tabular}

Table 13: Table Statement 10

\begin{tabular}{lllrl}
\hline & \multicolumn{2}{l}{ Observed data } & & \\
& SM & LPSEAG & Total & Expected \\
\hline Low & $\mathrm{a}=234$ & $\mathrm{~b}=275$ & 509 & 254.50 \\
High & $\mathrm{c}=335$ & $\mathrm{~d}=294$ & 629 & 314.50 \\
Total & 569 & 569 & 1138 & 569.00 \\
\hline
\end{tabular}

Table 14: Table Statement 11

\begin{tabular}{lllrl}
\hline & \multicolumn{2}{l}{ Observed data } & & \\
& - & & & \\
& SM & LPSEAG & Total & Expected \\
\hline Low & $\mathrm{a}=303$ & $\mathrm{~b}=201$ & 504 & 252 \\
High & $\mathrm{c}=266$ & $\mathrm{~d}=368$ & 634 & 317 \\
Total & 569 & 569 & 1138 & 569 \\
\hline
\end{tabular}

Table 15: Table Statement 12

\begin{tabular}{lllrl}
\hline & \multicolumn{2}{l}{ Observed data } & & \\
& - & & & \\
& SM & LPSEAG & Total & Expected \\
\hline Low & $\mathrm{a}=180$ & $\mathrm{~b}=204$ & 384 & 192 \\
High & $\mathrm{c}=389$ & $\mathrm{~d}=365$ & 754 & 377 \\
Total & 569 & 569 & 1138 & 569 \\
\hline
\end{tabular}

Table 16: Table Statement 13

\begin{tabular}{lllrl}
\hline & \multicolumn{2}{l}{ Observed data } & & \\
& --------------------------------- \\
& SM & LPSEAG & Total & Expected \\
\hline Low & $\mathrm{a}=241$ & $\mathrm{~b}=346$ & 587 & 293.50 \\
High & $\mathrm{c}=328$ & $\mathrm{~d}=223$ & 551 & 275.50 \\
Total & 569 & 569 & 1138 & 569.00 \\
\hline
\end{tabular}

Table 17: Table Statement 14

\begin{tabular}{lllrl}
\hline & \multicolumn{2}{l}{ Observed data } & & \\
& SM & LPSEAG & Total & Expected \\
\hline Low & $\mathrm{a}=269$ & $\mathrm{~b}=231$ & 500 & 250 \\
High & $\mathrm{c}=300$ & $\mathrm{~d}=338$ & 638 & 319 \\
Total & 569 & 569 & 1138 & 569 \\
\hline
\end{tabular}

Table 18: Table Statement 15

\begin{tabular}{|c|c|c|c|c|}
\hline & \multicolumn{4}{|c|}{ Observed data } \\
\hline & SM & LPSEAG & Total & Expected \\
\hline Low & $a=320$ & $b=215$ & 535 & 267.50 \\
\hline High & $c=249$ & $d=354$ & 603 & 301.50 \\
\hline Total & 569 & 569 & 1138 & 569.00 \\
\hline
\end{tabular}

\section{Conclusion and Future Work}

In this research, we developed a theoretical model which we called 'Programming in Social with in Affinity Group (LPSEAG)'. There is twofold for the contribution of this work. Firstly, it provide the first attempt of ARG model into Social media, thus supports students to learn programming in introductory programming courses within collaborative virtual learning environments. Second, extend ARG model to be a suitable for temporally and geographically distributed team over social media.

ARG is a collaborative model which builds to enhance the computer science students' learning in groups. Students with diverse backgrounds are components of ARG's groups. It is designed to be suitable for groups that operate physically in the same location. LPSEAG model builds on ARG model which is a highly successful model. In this study, we take the advantages of ARG model as a successful model to LPSEAG model as a virtual learning model over social media. In this study, we describe the LPSEAG model and the results of running an experiment, where we use the model for two academic years in the experiment to study the effect of the model on students' learning in the introductory programming courses.

The new proposed model adds a new value of virtual learning environments over social media. Students in the group can organize the learning timeline as they divide the process of learning programming to phases, each phase maps one of the software development system phases. Therefore, they practice working in teams to solve programming problems with different types of required steps.

\section{Author's Contributions}

Ahmad Al-Jarrah: Participated in all experiments, coordinated the data-analysis and contributed to the writing of the manuscript. Designed the research plan and organized the study, coordinated the mouse work.

Abdel Karim Baareh: Participated in all experiments, coordinated the data-analysis and contributed to the writing of the manuscript. Designed the research plan and organized the study. 
Ahmad Smadi and Roba Jabali: Participated in all experiments, coordinated the data-analysis and contributed to the writing of the manuscript.

\section{Ethics}

This article is original and contains unpublished material. The corresponding author confirms that all of the other authors have read and approved the manuscript and no ethical issues involved.

\section{References}

Al-Jarrah, A., \& Pontelli, E. (2014, October). " AliCeViLlagE" Alice as a Collaborative Virtual Learning Environment. In 2014 IEEE Frontiers in Education Conference (FIE) Proceedings (pp. 1-9). IEEE. https://doi.org/10.1109/FIE.2014.7044089

Al-Jarrah, A., \& Pontelli, E. (2016, July). On the effectiveness of a collaborative virtual pairprogramming environment. In International Conference on Learning and Collaboration Technologies (pp. 583-595). Springer, Cham. https://doi.org/10.1007/978-3-319-39483-1_53

Al-Jarrah, A. A. (2016). Collaborative virtual environments for introductory programming (cveip). New Mexico State University.

Al-Jarrah, A., \& Pontelli, E. (2020). The collaborative virtual affinity group model: principles, design, implementation and evaluation. International Journal of Computers and Applications, 42(5), 485-513. https://doi.org/10.1080/1206212X.2018.1486557

Arisholm, E., Gallis, H., Dyba, T., \& Sjoberg, D. I. (2007). Evaluating pair programming with respect to system complexity and programmer expertise. IEEE Transactions on Software Engineering, 33(2), 65-86. https://doi.org/10.1109/TSE.2007.17

Arora, A., Bansal, S., Kandpal, C., Aswani, R., \& Dwivedi, Y. (2019). Measuring social media influencer indexinsights from Facebook, Twitter and Instagram. Journal of Retailing and Consumer Services, 49, 86-101. https://doi.org/10.1016/j.jretconser.2019.03.012

Begel, A., \& Nagappan, N. (2008, October). Pair programming: what's in it for me?. In Proceedings of the Second ACM-IEEE international symposium on Empirical software engineering and measurement (pp. https://doi.org/10.1145/1414004.1414026

Constantine, L. L. (1995). Constantine on peopleware. Prentice Hall.

Dabbagh, N., \& Kitsantas, A. (2012). Personal Learning Environments, social media and self-regulated learning: A natural formula for connecting formal and informal learning. The Internet and higher education, $\quad 15(1)$, 3-8. https://doi.org/10.1016/j.iheduc.2011.06.002
Felder, R. M., \& Brent, R. (2007). Cooperative Learning. In the Active Learning: Models from the Analytical Sciences, Ed. PA Mabrouk. 34-53. https://doi.org/10.1021/bk-2007-0970.ch004

Galvin, S., \& Greenhow, C. (2020). Writing on social media: A review of research in the high school classroom. TechTrends, 64(1), 57-69. https://doi.org/10.1007/s11528-019-00428-9

Gates, A. Q., Teller, P. J., Bernat, A., Delgado, N., \& Della-Piana, C. K. (1999). Expanding participation in undergraduate research using the affinity group model. Journal of Engineering Education, 88(4), 409-414. https://doi.org/10.1002/j.21689830.1999.tb00467.x

Gates, A., Roach, S., Villa, E., Kephart, K., Della-Piana, C., \& Della-Piana, G. (2008). The affinity research group model: Creating and maintaining effective research teams. IEEE Computer society.

Greenhalgh, C. (2012). Large scale collaborative virtual environments. Springer Science \& Business Media. ISBN-10: 1447108671.

Guntuku, S. C., Buffone, A., Jaidka, K., Eichstaedt, J. C., \& Ungar, L. H. (2019, July). Understanding and measuring psychological stress using social media. In Proceedings of the International AAAI Conference on Web and Social Media (Vol. 13, pp. 214-225). https://ojs.aaai.org/index.php/ICWSM/article/view/3 223

Kephart, K. L., Villa, E. Q., Gates, A. Q., \& Roach, S. (2008). The affinity research group model: Creating and maintaining dynamic, productive and inclusive research groups. Council on Undergraduate Research Quarterly, 28(4), 13-24.

Kephart, K., \& Villa, E. (2008, October). Demonstrating sustainable success: Using ethnographic interviews to document the impact of the affinity research group model. In 2008 38th Annual Frontiers in Education Conference (pp. S2C-17). IEEE. https://doi.org/10.1109/FIE.2008.4720617

Khalid, S., Ullah, S., Ali, N., Alam, A., Rasheed, N., Fayaz, M., \& Ahmad, M. (2021). The effect of combined aids on users performance in collaborative virtual environments. Multimedia Tools and Applications, 80(6), 9371-9391. https://doi.org/10.1007/s11042-020-09953-9

Liebregt, M. (2005, January). Collaborative virtual environments in education. In 2nd Twente Student Conference on IT, Enschede (Vol. 21). http://web.stanford.edu/dept/SUSE/projects/ireport/arti cles/3D/2005_02_C_Liebregt,\%2520M.-

Collaborative_Virtual_Environments_in_education.pdf

McDonald, J. H. (2009). Handbook of biological statistics (Vol. 2, pp. 6-59). Baltimore, MD: sparky house publishing. $\quad$ http://www.uni-koeln.de/math-natfak/genetik/groups/Langer/HandbookBioStatSeco nd.pdf 
McDowell, C., Werner, L., Bullock, H., \& Fernald, J. (2002, February). The effects of pair-programming on performance in an introductory programming course. In Proceedings of the 33rd SIGCSE technical symposium on Computer science education (pp. 38-42). https://doi.org/10.1145/563340.563353

Nawrocki, J., \& Wojciechowski, A. (2001). Experimental evaluation of pair programming. European Software Control and Metrics (Escom), 99-101. http://citeseerx.ist.psu.edu/viewdoc/download?doi=1 0.1.1.19.1689\&rep=rep $1 \&$ type $=$ pdf

Park, M. (2019). Facebook reports third quarter 2019 results. https://s21.q4cdn.com/399680738/files/doc_financia 1s/2019/q3/FB-Q3-2019-Earnings-Release.pdf

RabbitMQ. (2015). RabbitMQ is the most widely deployed open source message broker. RabbitMQ. https://www.rabbitmq.com

Redfern, S., \& Naughton, N. (2002). Collaborative virtual environments to support communication and community in internet-based distance education. Journal of Information Technology Education: Research, 1(1), 201-211. https://doi.org/10.28945/356

Ricciardelli, L. A., Nackerud, L., Quinn, A. E., Sewell, M., \& Casiano, B. (2020). Social media use, attitudes and knowledge among social work students: Ethical implications for the social work profession. Social Sciences \& Humanities Open, 2(1), 100008. https://doi.org/10.1016/j.ssaho.2019.100008

Riehm, K. E., Feder, K. A., Tormohlen, K. N., Crum, R. M., Young, A. S., Green, K. M., ... \& Mojtabai, R. (2019). Associations between time spent using social media and internalizing and externalizing problems among US youth. JAMA psychiatry, 76(12), 1266-1273. https://doi.org/10.1001/jamapsychiatry.2019.2325
Sandoval, M., Morris, T., \& Turner, M. (2020). Interaction Framework within Collaborative Virtual Environments for Multiple Users each interacting with Multiple Degrees-Of-Freedom Controllers. http://diglib.eg.org/bitstream/handle/10.2312/cgvc20 201155/079-081.pdf?sequence=1\&isAllowed=y

Sarwar, B., Zulfiqar, S., Aziz, S., \& Ejaz Chandia, K. (2019). Usage of social media tools for collaborative learning: The effect on learning success with the moderating role of cyberbullying. Journal of Educational Computing Research, 57(1), 246-279. https://doi.org/10.1177/0735633117748415

Storey, M. A., Singer, L., Cleary, B., Figueira Filho, F., \& Zagalsky, A. (2014). The (r) evolution of social media in software engineering. In Future of Software Engineering Proceedings (pp. 100-116). https://doi.org/10.1145/2593882.2593887

Treude, C., Figueira Filho, F., Cleary, B., \& Storey, M. A. (2012). Programming in a socially networked world: the evolution of the social programmer. The Future of Collaborative Software Development, 1-3. https://ctreude.files.wordpress.com/2012/01/progr amming_in_a_socially_networked_world.pdf

Voorn, R. J., \& Kommers, P. A. (2013). Social media and higher education: Introversion and collaborative learning from the student's perspective. International journal of social media and interactive learning environments, 1(1), 59-73. https://doi.org/10.1504/IJSMILE.2013.051650

Zhang, X., Ma, L., Xu, B., \& Xu, F. (2019). How social media usage affects employees' job satisfaction and turnover intention: An empirical study in China. Information \& Management, 56(6), 103136. https://doi.org/10.1016/j.im.2018.12.004 